\title{
Firing Costs and Job Loss: The Case of the Italian Jobs Act
}

\author{
Claudia Pigini $^{1}\left(\mathbb{D} \cdot\right.$ Stefano Staffolani $^{2}$
}

Received: 17 November 2020 / Accepted: 10 May 2021 / Published online: 29 May 2021

(c) The Author(s) 2021

\begin{abstract}
A recent reform in the Italian labour market has modified the permanent contract by reducing firing costs. Using a discontinuity in the application of the reform, we evaluate its effect on the probability of being still employed about three and a half years later. In contrast with theoretical predictions, we find that the job survival probability is not smaller for the treated and even significantly larger in some cases. We investigate the composition of permanent workers hired after the reform and we find evidence of treated firms changing their recruitment strategy in favour of potentially more productive workers.
\end{abstract}

Keywords Deregulation · Employment protection legislation · Graded security Open-ended contracts

JEL Classification J23 $\cdot$ J30 $\cdot$ J41

\section{Introduction}

The Italian labour market has been traditionally characterised by a strong protection against dismissal of permanent workers. The employment protection legislation has generated a harsh and continuous debate between unions, entrepreneurs and governments. The focal point of the debate is Article 18 of the Workers Statute, ${ }^{1}$ which compelled the employer, in firms with 15 employees or more, to reinstate the worker or to a compensation of 15 months pay following an unfair dismissal certified by a court ruling. A modification of Article 18 in 1990 provided the possibility of reinstatement

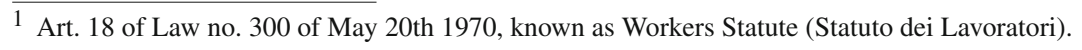

$凶$ Claudia Pigini

c.pigini@univpm.it

Stefano Staffolani

s.staffolani@univpm.it

1 Department of Economics and Social Sciences, Marche Polytechnic University, 60121 Ancona, Italy

2 Department of Economics and Social Sciences, Marche Polytechnic University, Ancona, Italy 
alternatively to a lower severance payment for firms with less than 15 employees, ${ }^{2}$ while firms with 15 employees or more had to reinstate the worker in case of certified unfair dismissal. Nonetheless, in 2013 the OECD still accounted Italy as one of the countries with highest degree of protection of permanent workers against individual and collective dismissals (OECD 2013).

In an attempt to loosen the employment protection legislation, the Law no. 183 of December 20th 2014, also known as the Jobs Act, defined a new type of contract for permanent workers hired in firms with 15 employees or more, know as the increasing protection contract (contratto a tutele crescenti, IPC hereafter). The new open-ended contract limits reinstatement to discriminatory and very specific disciplinary dismissals, thereby excluding from unfair dismissals those occurring for economic reasons. It also introduces a compulsory severance payment in case of layoff, which is flat and equal to 4 months pay for the first 2 years of service and then proportional to tenure with a maximum of 24 months pay. This new type of contract reduces not only the expected amount of firing costs but also their uncertainty, because the cost faced by firms in case of dismissals is no longer subject to the arbitrariness of court decisions (Sestito and Viviano 2018). Workers were hired under the new IPC starting March 7th 2015. As a matter of fact, the Jobs Act was a broader reform that introduced also other important changes in the Italian labour market legislation. In particular, a 3-year reduction of the social contribution paid by the firm was applied to new permanent contracts starting January 1 st 2015 , which entailed a sizeable reduction in non-wage labour costs for 3 years. Workers eligible for this tax rebate were those not employed with an open-ended contract in the 6 months prior to the new contract.

The reduction of firing costs brought by the Jobs Act was not well received by unions and, in general, it was harshly criticised in the media. According to the Secretary of the Italian main union (CGIL) the Jobs Act "liberalises layoffs and makes the permanent contract precarious". 3 This opinion found supporters in the Italian system of industrial relations and in the political arena. Unions and left parties demanded an abrogative referendum, that the Constitutional Court has in fact declared inadmissible.

The aim of this paper is to evaluate whether the new IPC introduced by the Jobs Act made permanent contracts more precarious, by investigating whether the reform decreased the probability of still being employed in the same firm approximately three and a half years after being hired (specifically 1333 days). Our identification strategy exploits the firm size threshold of 15 employees entailed by the reform, with workers hired in firms with more than 15 employees after March 7th representing the treated group. The empirical analysis is based on the administrative data LOSAI, released by the Ministry of Labour and Social Policies together with the National Social Insurance Agency (INPS). The database contains working histories on a sample of Italian workers up to November 2018, from which we select permanent contracts signed in the 9 weeks - window around the introduction of the IPC.

\footnotetext{
2 Law no. 108 of May 11th 1990 established severance payments between 2.5 and 6 months pay under 10 years for tenure, up to 10 for workers with 10-20 years of tenure, 14 for more than 20 years of tenure.

3 Audition at the Chamber of Deputies, Labour Commission, January 27th 2015.
} 
From the theoretical point of view, a stricter employment protection legislation implies that the optimal strategy for the firm is to reduce both hirings and separations (Ljungqvist 2002), or insignificantly increase firms marginal propensity to hire (Bentolila and Bertola 1990). The overall effect on employment is however ambiguous, other than a clear reduction of job mobility (Cahuc and Postel-Vinay 2002; Autor et al. 2007). Moreover, with higher firing costs, firms may prefer hiring workers who are already screened and therefore less likely to be lemons (Kugler and Saint-Paul 2004). Therefore it may be conjectured that lowering firing costs may increase firms propensity to hire permanent workers characterised by a lower average and a greater variance in their expected productivity.

Treated workers are therefore less costly to dismiss and are expected to be less productive, which puts them at a higher risk of contract termination. Furthermore, in the specific case of the Jobs Act, employees in large firms are aware that seeking a better job position after March 7th 2015 implies giving up the old contract (regulated by Article 18) for the new deregulated one. This could translate into a lower willingness to seek a new job and into a reduction of voluntary resignations. Workers hired after March 7th in firms with 15 employees or more should therefore face a lower employment survival probability compared to untreated workers, due to both a greater risk of dismissal and a higher propensity to resign voluntarily.

Because the Italian Jobs Act is a very recent reform, the empirical literature evaluating its effects on labour demand is still limited. The only evidence of the effects of the new firing rules on the firing rate is provided by Boeri and Garibaldi (2019). Using firm-level data, they find a significant increase in firings, which amounts to approximately $50 \%$ more with respect to the control group. They also find an increase of about $60 \%$ in the hiring rate. We argue that focusing only on firings may be misleading, because the Jobs Act may have changed the relative appeal of firing versus voluntary resignation in the case of dismissals for economic reasons. This is because, with the previous legislation, fired workers could easily appeal to courts to challenge the dismissal decisions and the judge could force employers to reinstate them or to pay heavy and unpredictable penalties. With the Jobs Act, the threat of appeal became less credible because firing rules were set more clearly. Furthermore, the Jobs Act changed the modality of resignation, which is now an on-line procedure aimed at eliminating the phenomenon of white resignations (dimissioni in bianco). In essence, it is a deplorable practice with which some employers force just-hired workers to sign an undated letter of resignation, that the employer can later use to dismiss the employee, thus avoiding to face the arbitrariness of court decisions and the risk of reinstatement.

Further descriptive evidence on the Jobs Act based on aggregate data is provided by Cirillo et al. (2017), who show that the reduction of firing costs did not affect the dynamics of new open-ended contract. By contrast Sestito and Viviano (2018), using employer-employee data for the Veneto region, find an increase in hirings following March 7th 2015 of about 8\%. They also find that the reduction of firing costs increased the propensity to offer permanent job positions to workers unknown to firms that, under the old firing rules, might have preferred to test prospective permanent employees with a temporary position. Effects of changes in firing costs on dismissal probability in Italy have also been evaluated with respect to the modifications of Article 18 in 1990. In particular, Boeri and Jimeno (2005) and Kugler and Pica (2008) found that increasing 
firing costs for small firms brought a significant decrease in separations (of about $14 \%$ according to Kugler and Pica 2008).

We find that there is a slightly but significantly larger probability of still being employed 1333 days after the job started between the treated and the control group although, in some cases, this difference is not statistically significant. This contradicts the common feeling of an increased vulnerability of the new permanent workers and seems to be in contrast with earlier findings on the effects of firing costs on separations and with the empirical results presented by Boeri and Garibaldi (2019) on firings based on firm level data. It is worth mentioning that they do not disentangle which workers are causing the firing rate to increase after the reform, whether are those hired with the old or new permanent contract. It must be stressed that in this work we do not analyse the dismissal rate, but the different probability of exit for permanent workers recruited under the old legislation and those hired with the IPC contract.

We investigate several potential mechanisms generated by the Jobs Act that may have triggered this apparently puzzling result. We first look into separating firings from voluntary resignations in order to assess whether our results are driven by a change in the latter after the introduction of the new IPC. In light of the recent findings by Boeri and Garibaldi (2019), it may be argued that the reduction of firing costs could have decreased the relative convenience of voluntary resignations, thereby compensating a higher firing rate. Another possible explanation is that during upturns voluntary resignations in small firms may increase, as workers prefer to move to large firms that offer higher wages (Moscarini and Postel-Vinay 2012), the non-lower surviving probability of the IPC workers could depend only on a higher voluntary resignation rate in small firms after the IPC reform. Secondly, the reduction of firing costs may have made relatively more convenient for firms to substitute with the new IPC the previous common practice of hiring temporary workers, screen them, and then transform them into permanent ones (Sestito and Viviano 2018). This should make us observe a non-negative average treatment effect if the duration of could-have-been temporary contracts was supposed to be longer than the 1333 days from recruitment, at which we evaluate the probability of still being employed. The transformation of temporary contracts may also play a role, in that it is more convenient for large firms to transform them, if they intended to do so, after the introduction of the IPC, in order to exploit the reduction of firing costs and the rebate on non-wage labour costs, where applicable, that goes with permanent positions. If these transformations occur for more productive workers, who supposedly have a higher probability of being employed 1333 days after recruitment, then the average effect could also be non-negative.

Thirdly, the incentive to hire workers on a permanent basis due to the reduction of per-period non-wage labour costs may have been more effective when, due to the IPC, the costs of dismissal were reduced. Many commentators argue that it was the combination of the two policies that fostered labour demand since 2015, as reported by Sestito and Viviano (2018). Treated firms may therefore have increased the share of permanent workers hired with the incentive after the introduction of the IPC, which might reflects on the larger survival probability of these hirings occurred for more productive workers.

Finally, we conjecture that with lower firing costs, because of the higher propensity to recruit unscreened workers, new permanent employees have a more volatile 
productivity distribution than those hired with the old contract. If this is the case, in presence of a negative shock in the short run, firms will prefer to dismiss workers hired with lower firing costs and in the left tail of the productivity distribution. However, in the medium-run, the remaining new workers may have a higher productivity level than employees under the old firing rules and, in presence of a negative shock, firms may choose to dismiss the latter, even with higher firing costs. ${ }^{4}$

We attempt a test of these theories based on the available data. Among our conjectures, the results seem to be driven only by the firms higher propensity to recruit young and unknown workers after the reform, who may turn out to be more productive and therefore less likely to be dismissed in the medium run, whereas none of the results based on the other assumptions provide any clear insights.

The rest of the paper is organised as follows: Sect. 2 describes the data; Sect. 3 describes the identification strategy; in Sect. 4 we report and discuss the estimation results along with falsification exercises and robustness checks; Sect. 5 provides a discussion of the results and some evidence on the mechanisms generating a larger survival probability with the new IPC; Sect. 6 concludes.

\section{The LoSai Database}

The Italian Institute of Social Security (INPS) collects administrative data on the universe of Italian dependent workers. The Italian Ministry of labour and social policies periodically extracts the LOSAI from the administrative archive. ${ }^{5}$ LOSAI contains information on the contracts signed, transformed, renewed and ceased referring to workers born on the 1st and 9th day of each month, that amount to $6.5 \%$ of the workers population. For each contract, information refer to the starting date, the ending date (if any), the type of contract, the type of working time arrangement, the hiring and dismissal reasons, and the worker's qualification. Firms and employees characteristics can be matched, such as firm size and sector and worker age, gender, qualification and region of residence. Workers education is unfortunately not available. In the empirical analysis, we will also use the worker's years of experience and years of tenure, evaluated at the end of 2014.

We select the permanent contracts signed during the nine weeks before and after the change in firing costs on March 7th, that are all contracts signed between the January 3rd and May 8th 2015. Weeks start on Saturdays, as it March 7th was a Saturday. The choice of the 18 weeks window depends on the left threshold. In fact, on January 1st, firms could start applying for the hiring subsidy that was also part of the Jobs Act, that is the 3 year reduction of social security contributions on permanent employment contracts signed between January 1st to December 31st 2015. For more details about the whole reform package and the timing of the implementation of the different measures, we refer the reader to Sestito and Viviano (2018); Boeri and

\footnotetext{
${ }^{4}$ Similar implications are suggested by Martins (2009), based on quasi-experimental evidence for the introduction of a higher flexibility in dismissals in Portugal: he finds that a reduction in firing costs boosts firms performance, which may arise from an increase in workers' effort.

5 More information at the ClicLavoro web page https://www.cliclavoro.gov.it/Barometro-Del-Lavoro/ Pagine/Microdati-per-la-ricerca.aspx
} 
Table 1 New contracts before and after March 7th 2015 by firm size

\begin{tabular}{lllll}
\hline & & Contracts & Contracts $(\%)$ & Employed \\
\hline Before & Small & 3245 & 19.19 & 0.44 \\
Before & Large & 5295 & 31.31 & 0.49 \\
After & Small & 3078 & 18.20 & 0.40 \\
After & Large & 5296 & 31.31 & 0.52 \\
Total & & 16,914 & 100 & 0.47 \\
\hline
\end{tabular}

Garibaldi (2019). Because this measure can be an important confounder in the analysis of the effects of firing costs, the choice of the window ensures that all the workers, whether in the treated or in the control group, are eligible for the subsidy. ${ }^{6}$ In order to keep some degree of homogeneity in our sample, we limit our analysis to firms with more than 6 employees. It is also worth mentioning that the information on firm size refers to the average number of employees in 2014. As argued by Boeri and Garibaldi (2019), the definition of the threshold is nontrivial if this is varying around the time of the reform, especially for firms with a number or employees close to 15 .

We start with 24,021 observations in the 18 weeks window, from which we select full-time jobs, we exclude top managers, interim and on-call work contracts, we leave out those signed in agriculture sector, for which the new firing costs applied in firms with more than 5 employees. We also drop new contracts and terminations resulting from a direct transfer within the same company, contracts started after a leave due to union activities, and contracts ended because of the worker's death. Finally, we drop observations for which we had missing workers, contract or firm characteristics. Our final sample consists of 16,914 full-time permanent contracts.

Table 1 reports the frequency of permanent contracts that started in the 9 weeks before and after the implementation of the new firing rules, May 7th 2015, by firm size, as the reform affected only those employing 15 workers or more. In the table and throughout the paper, we refer to firms with less and more than 15 employees as small and large firms, respectively. The last column of Table 1 reports the frequency of workers still employed in the same firm 1333 days after they are hired, that is our outcome variable of interest. 1333 days is the furthest we are able to observe the working histories in LOSAI for those who are hired in the last day of the 18 weeks window. It emerges that this frequency is higher for workers employed in large firms and lower for workers employed in small firms after the reform.

Table 2 reports averages of individual characteristics, workers qualification, and contract characteristics before and after the reform, by firm size. After the reform, large firms seem more likely to hire younger workers than small firms. It is also worth noticing that, as concerns qualifications, the composition of hired workers in small and large firms does not seem to be substantially affected by the reform. Finally, it is interesting to note that the share of contracts characterised by a reduction in social

\footnotetext{
6 It is worth to clarify that the different choice of the time window in Boeri and Garibaldi (2019) is driven by data availability, being theirs referred to firms and not to job contracts.
} 
Table 2 Descriptive statistics on workers characteristics before and after March 7 th 2015 by firm size

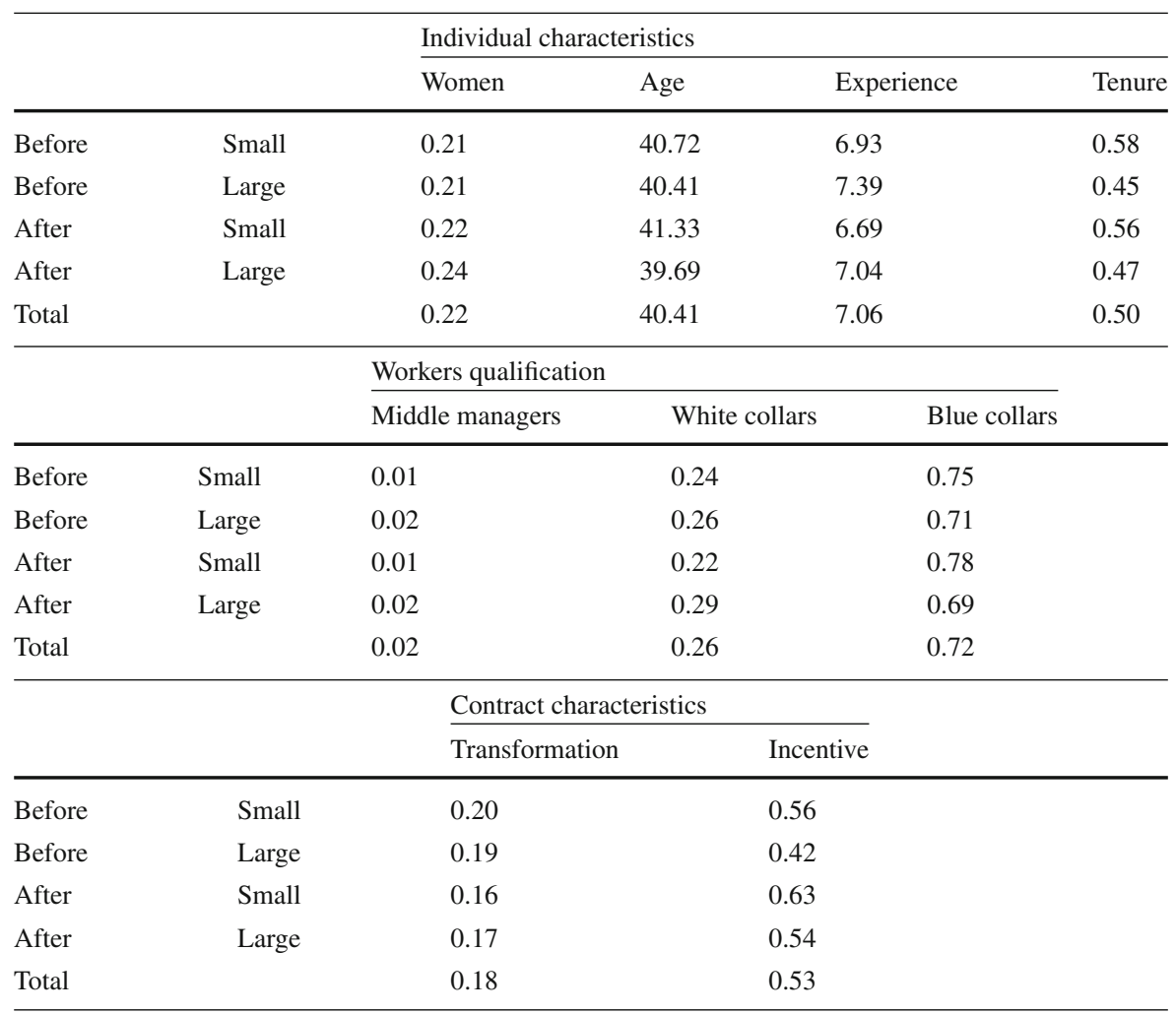

contribution (Incentive, as flagged in the LoSai database) increases after the reform, in both small and large firms. ${ }^{7}$

Figure 1 depicts the Kaplan-Meyer survival probabilities by the four groups divided according to firm size and reform implementation. The figure in the left panel is based on data referring to the contracts signed between January 1st and May 8th 2015, whereas the figure in the right panel refers to the same window taken in 2014, when no labour market reforms were in place. It emerges that survival probabilities are lower in small firms and workers hired after the job act in small firms seem to have significantly lower survival probabilities. In large firms, differences between survival probabilities seem to appear around one year after recruitment, with treated workers showing a slightly higher survival probability than untreated ones. In 2014 instead,

7 The document "I contratti di lavoro dopo il Jobs Act" (2016) issued by the Ministry of Labour and Social Policies, shows that the ratio between new permanent contracts with contribution exemption and total new permanent contracts in the period January-May 2015 is equal to 53\%, in line with our descriptives. According to Gambuzza et al. (2020), the flow of recruitment without the rebate concerns a significant portion of workers who, despite having permanent contracts, are employed by companies that work in subcontracting (typically in logistics and cleaning sectors) and frequently find themselves changing employers, with short or no time intervals between one work relationship and the next. There are also workers who, due to their skills and experience gained, meet a demand willing to recruit them regardless of the presence of incentives. 
2015

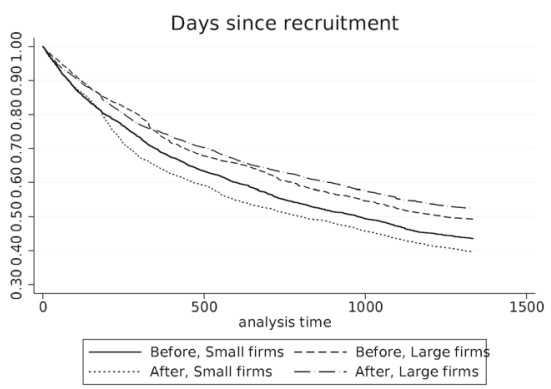

2014

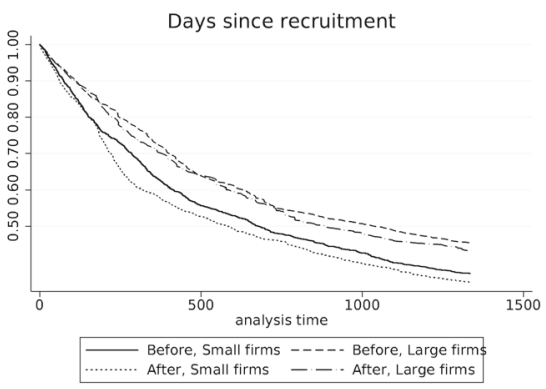

Fig. 1 Kaplan-Meyer survival probability estimates before and after May 7th

workers hired after March 7th exhibit a lower survival probability than those hired before that date. It can also be noticed that for small firms in both 2014 and 2015 there is a drop in the survival probability about 180 days after signing the contract for workers hired after the 7th May. This is probably due to the fact that small firms may have hired seasonal workers for the summer with permanent contracts. The sectors of commerce and catering are in fact the main cause for this drop. In order to account for within-industry correlation between unobserved components, the standard errors for the reported treatment effects in Section 4 are clustered at the 2digit-sector level.

\section{Identification Strategy}

The identification of the effect of lower firing costs on the probability of being employed 1333 days after being hired is based on a difference-in-difference approach with repeated cross-sections.

Let $h_{i t}$ be a binary variable equal to 1 if worker $i$ hired at time $t$ is still employed in the same firm 1333 days after the job started and 0 otherwise. Let us also define $D_{i}$ as a binary variable equal to 1 if worker $i$ is hired in a firm with 15 employees or more and 0 otherwise, and $R_{i}$ as a dummy variable equal to 1 if worker $i$ is hired after the reform implementation on March 7th 2015. We set up the following linear regression model

$$
h_{i t}=\beta_{0}+\beta_{1} D_{i}+\beta_{2} R_{i}+\beta_{3} D_{i} \times R_{i}+\mathbf{x}_{i}^{\prime} \boldsymbol{\beta}_{4}+\mathbf{z}_{i t}^{\prime} \boldsymbol{\beta}_{5}+\varepsilon_{i t},
$$

where $D_{i} \times R_{i}$ is the binary treatment and $\beta_{3}$ is the average treatment effect on the treated (ATET). Vector $\mathbf{x}_{i}$ contains worker's exogenous or pre-treatment characteristics, such as gender, age, years if experience and years of tenure at the end of 2014, region of residence, and qualification (blue collar, white collar, middle manager, other). The available information on the worker's qualification refers to the job considered in the analysis. We consider this information exogenous because, given that the qualification is classified in only 4 categories, switching between these classes due to different firing costs is highly unlikely, especially since firing costs were not differentiated between occupations. We rather use this variable as a proxy of the worker's skill level, 
in absence of any information on the level of educational attainment. In addition, we include in $\mathbf{x}_{i}$ two contract characteristics, namely a dummy variable for whether the worker was hired with the incentive on non-labour costs in place since January 1st 2015, and a dummy variable equal to 1 for whether the permanent contract is a result of a transformation a temporary contract that took place in the last month. Vector $\mathbf{z}_{i t}$ includes controls for the day of the recruitment, that are the day of the week and the day of the month worker $i$ is hired and a linear time trend.

Further to the exogeneity of the explanatory variables in (1), the identification of the treatment effect of interests relies on other two key assumptions (see Angrist and Pischke 2009; Lechner 2011). One is the no anticipation assumption, according to which in the pre-treatment period, the treatment has no effect on the outcome of the pre-treatment population. It is difficult to argue whether there may be anticipatory effects in our setting and, if so, in which direction they affect the outcome of the pre-treatment group. As the policy was announced in December 2014, during the first 2 months of 2015 prospective employees may have been more likely to look for a job before the reform implementation, when the employment protection legislation was stricter, thereby supposedly increasing their probability of still being employed 1333 days later. At the same time, though, firms may hold off hirings until firing costs are lower. In order to check the robustness of our main result to potential anticipatory effects, in Sect. 4.1 we report an exercise where we build the pre-treatment population by considering workers hired in the first 9 weeks of 2014 .

The second identifying assumption is common or parallel trend assumption, according to which the probability of being employed 1333 days after the job started should have the same trend over time for workers hired in small and large firms. This way, the discrepancy between the before-after average differences for the workers employed in small and large firms can be ascribed only to the treatment and not confounded by the different evolution over time of employment survival probability in the two groups. There is no definitive way to test for this assumption. It can be inspected by graphical analysis and supported by the results of the auxiliary regression function proposed by Autor (2003). The results of this exercise are also reported in Sect. 4.1.

Finally, it is worth to underline that the choice of the linear probability model in (1) over alternative generalised linear models for binary responses, such as logit or probit model, is driven by two main advantages brought by the former, especially within the difference-in-difference framework. First, coefficients can be shown to be accurate approximations of the average marginal effects that can be obtained with a probit model (Wooldridge 2010). Moreover, with non-linear models one must also beware of interaction terms, as they may be unable to produce the correct sign of the marginal effect (Ai and Norton 2003). Although Puhani (2012) shows that in the case of difference-in-difference the sign of the causal effect of interest is correctly identified, still the quantification of its standard error is not directly available. The second, and probably more important, argument in favour of the linear probability model for the difference-in-difference setting resides with the verification of the identifying parallel trend assumption. In practice, the common trend the assumption is based on differencing out trends in the treatment and control group which, as discussed in depth by Lechner (2011), is not possible with a non-linear specification. Within the differencein-difference framework, a non-linear model specification, would therefore lead to an 
inconsistent estimator of the causal effect because, even if the standard identifying assumptions hold, such formulation would violate them, unless additional restrictions on the parameters are set (Lechner 2011).

\section{Empirical Results}

In the following, we first present the main estimation results and falsification exercises aimed at assessing the viability of our identifying assumptions. Then, we turn to some robustness checks concerning the choice of the time window around the reform implementation, the sample selection based on firm size, and some specification choices. The full set of estimation results is available in Appendix 2.

\subsection{Main Results and Falsification Exercises}

The estimation results based on the difference-in-difference estimates are reported in Table 3, where the columns correspond to different specifications based on the choice of controls. In contrast with the theoretical prediction, we find that being hired with lower firing costs does not reduce the probability of being employed with the same job 1333 days after the contract started, with respect to being hired with a stricter employment protection legislation.

The average outcome probability for workers employed in small firms before March 7 th, that is $\beta_{0}$, is between 0.17 and 0.50 across the specifications considered and differences between large and small firms in the same period, $\beta_{1}$, are always positive and statistically significant. It is also worth noticing that, on average, the difference between after and before March 7th in the outcome probability for small firms, $\beta_{2}$, disappears when time effects are controlled for. Finally the ATET, $\beta_{3}$, is positive and its magnitude is reduced by the inclusion of covariates. According to the results in column (4), workers hired in firms with 15 employees or more have, on average, a probability of still being employed 1333 days later that is 3.3 percentage points higher than those hired with a stricter employment protection legislation.

The reliability of this result rests on the identifying assumptions needed for the consistency of the difference-in-difference estimator. As discussed in Sect. 3, one of these requirements is the no anticipation assumption, by which the treatment must not have any affect on the outcome of the pre-treatment population. As a matter of fact, the reform was announced well before March 7th becoming common knowledge for both workers and firms prior to its implementation. As mentioned in Sect. 1, this awareness may have pushed large firms to postpone hirings, limiting recruitment before the reform only to workers that are less likely to be lemons. If this is the case, then the effect on the after-treatment composition of hired workers, who are more likely to be unscreened and have a greater probability of being less productive, should lead to an estimated ATET that represents a lower bound for the true effect of the reform.

Although this assumption cannot be tested directly, we report the result of a placebo test in Table 4, which can help assess its viability. The first column reports differencein-difference estimates based on a sample where the pre-treatment period is taken 


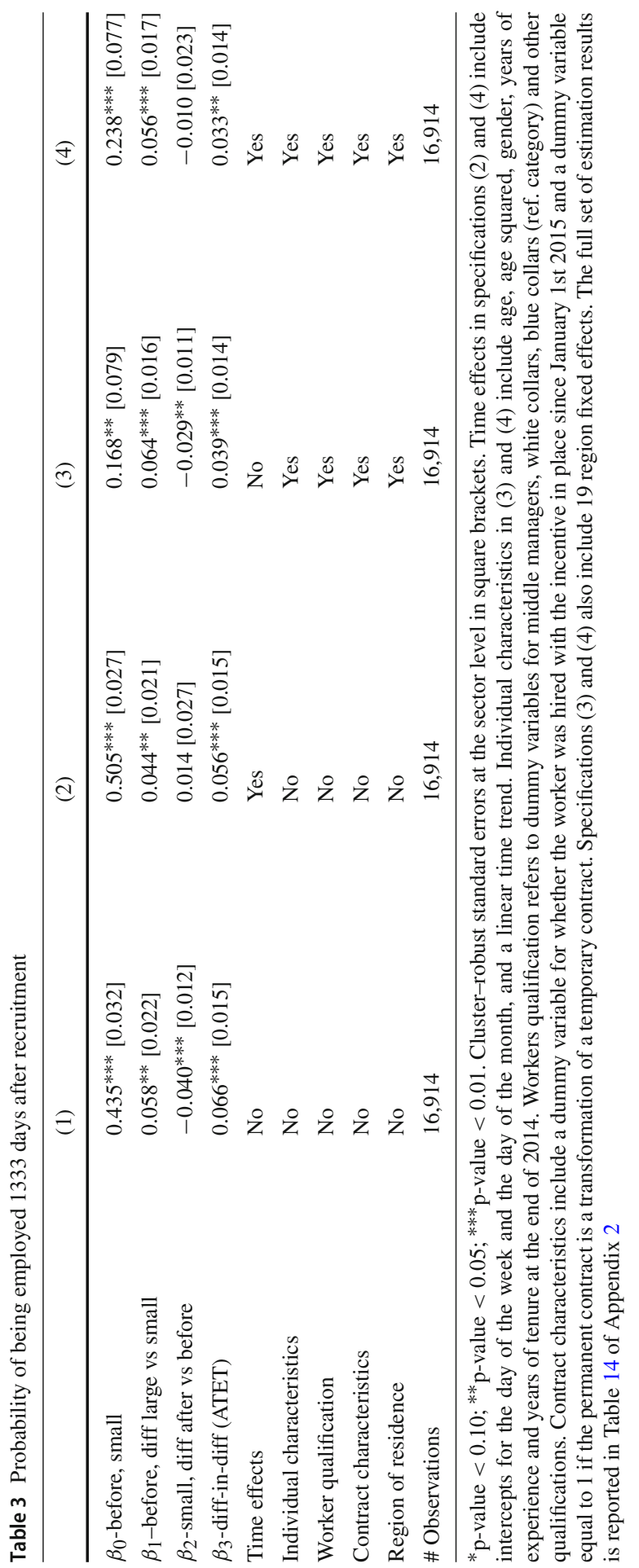


Table 4 Probability of being employed 1333 days after recruitment: placebo tests

\begin{tabular}{lll}
\hline & $2014 / 1 / 3-2014 / 3 / 6$ & $2014 / 1 / 3-2014 / 3 / 6$ \\
& $2015 / 3 / 7-2015 / 5 / 8$ & $2014 / 3 / 7-2014 / 5 / 8$ \\
\hline$\beta_{0}$-before, small & $0.098[0.081]$ & $0.066[0.106]$ \\
$\beta_{1}$-before, diff large vs small & $0.068^{* * *}[0.020]$ & $0.072^{* * *}[0.019]$ \\
$\beta_{2}$-small, diff after vs before & $0.022[0.025]$ & $0.006[0.029]$ \\
$\beta_{3}$-diff-in-diff (ATET) & $0.020[0.025]$ & $-0.008[0.024]$ \\
$\#$ Observations & 14,004 & 10,414
\end{tabular}

${ }^{*}$ p-value $<0.10 ;{ }^{* *}$ p-value $<0.05 ;{ }^{* * *}$ p-value $<0.01$. Cluster-robust standard errors at the sector level in square brackets. Both specifications include time effects, individual and contract characteristics, workers qualification, and region fixed effects (see Table 3 for details). The full set of estimation results is reported in Table 15 of Appendix 2
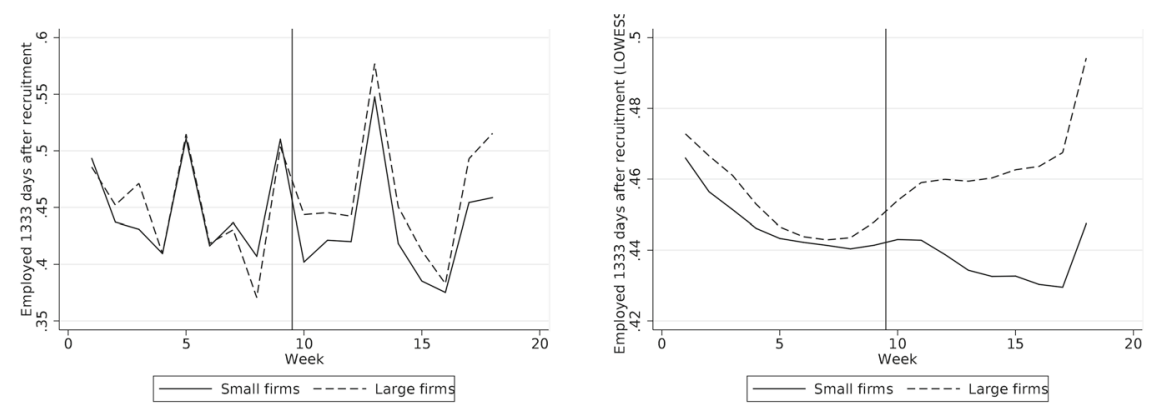

Fig. 2 Share of workers still employed 1333 days after recruitment: small and large firms

in 2014 (from January 3rd to March 6th), when the reform was not in place nor announced. The results again suggest no effect of the treatment. For completeness, the second column of Table 4 reports the result of a proper placebo test, where differencein-difference estimates are based on the same 18 weeks window taken in 2014. As expected, being hired before or after May 7th 2014 makes no difference on the probability of being employed 1333 days later, not even between small and large firms.

The second identifying assumption is the common trend assumption, according to which the outcome variable in small and large firms before the treatment should share the same evolution over time. One way to check for the presence of a common trend is by performing a graphical analysis (Angrist and Pischke 2009). The left panel of Fig. 2 reports the fitted share of workers still employed in the same job position 1333 days estimated by means of two separate linear regression models, one for small and one for large firms. Model specifications include time effects, individual characteristics, worker qualification, region and sector fixed effects. From the figure, no relevant differences seem to emerge in the evolution of the share of workers still employed after 1333 days between small and large firms before the treatment date, represented by the vertical line. Descriptive evidence of a pre-treatment common underlying trend is also provided by the right panel of Fig. 2, where predictions are obtained by a locally weighted regression. 
Another common practice used to check for common trends is to follow Autor (2003) and specify the following auxiliary regression

$$
\begin{aligned}
h_{i t}= & \gamma_{0}+\gamma_{1} D_{i}+\sum_{s=1}^{S} \gamma_{2 s} 1\{t=s\}+\sum_{s=1}^{M} \gamma_{3 s} 1\{t=s\} D_{i} \\
& +\sum_{s=M+1}^{S} \gamma_{4 s} 1\{t=s\}+\sum_{s=M+1}^{S} \gamma_{5 s} 1\{t=s\} D_{i}+\mathbf{x}_{i}^{\prime} 6+v_{i t},
\end{aligned}
$$

where $h_{i t}$ is the outcome variable for worker $i$ hired at time $t$ and the set of regressors contains time dummies and interaction terms between the time dummies and firm size. With the above notation, we separate the interaction effects in the $M$ time occasions before the treatment occurred, $\gamma_{2 s}, \gamma_{3 s}$ with $s=1, \ldots, M$, and in those after the treatment, $\gamma_{4 s}, \gamma_{5 s}$ with $s=M+1, \ldots, S$. The parametrization using interaction terms induces heterogeneity between the treated and the control group in the conditional expectation of the outcome given time. More formally, for the control group we have

$$
\mathrm{E}\left[h_{i t} \mid D_{i}=0, t, \mathbf{x}_{i}\right]=\gamma_{0}+\sum_{s=1}^{S} \gamma_{2 s} 1\{t=s\}+\sum_{s=M+1}^{S} \gamma_{4 s} 1\{t=s\}+\mathbf{x}_{i 6}^{\prime},
$$

whereas for the treated we have

$$
\begin{aligned}
\mathrm{E}\left[h_{i t} \mid D_{i}=1, t, \mathbf{x}_{i}\right]= & \gamma_{0}+\gamma_{1}+\sum_{s=1}^{S} \gamma_{2 s} 1\{t=s\}+\sum_{s=1}^{S} \gamma_{3 s} 1\{t=s\} \\
& +\sum_{s=M+1}^{S} \gamma_{4 s} 1\{t=s\}+\sum_{s=M+1}^{S} \gamma_{5 s} 1\{t=s\}+\mathbf{x}_{i}^{\prime} 6 .
\end{aligned}
$$

The above formulations clarify that the difference between time effects for the treated and the control group amount to the parameters $\gamma_{3 s}$, for $s=1, \ldots, M$, before and to the parameters $\gamma_{5 s}, s=M+1, \ldots, S$, after the introduction of the IPC. If the common trend assumption holds, meaning that the evolution of the outcome variable conditional on $\mathbf{x}_{i}$ before the treatment is the same for the treated and control group, the null hypothesis $H_{0}: \gamma_{31}=\cdots=\gamma_{3 M}=0$ should not be rejected.

Figure 3 plots the estimated coefficients $\hat{\gamma}_{3 s}, s=1, \ldots, M$, and $\hat{\gamma}_{5 s}, s=M+$ $1, \ldots, S$, based on a regression where the time occasions are the weeks between January 3rd and may 8th 2015 with their $95 \%$ confidence intervals: all but one of the coefficients before the treatment are not statistically significant. The formal $F$-test for the null hypothesis $H_{0}: \gamma_{31}=\cdots=\gamma_{3 M}=0 F(9,16849)=0.79$ with the associated p-value equal to 0.63 . We therefore conclude that, in this case, there is not enough evidence to consider the common trend assumption unsatisfied. ${ }^{8}$

\footnotetext{
8 The full set of estimation results is available upon request from the authors.
} 


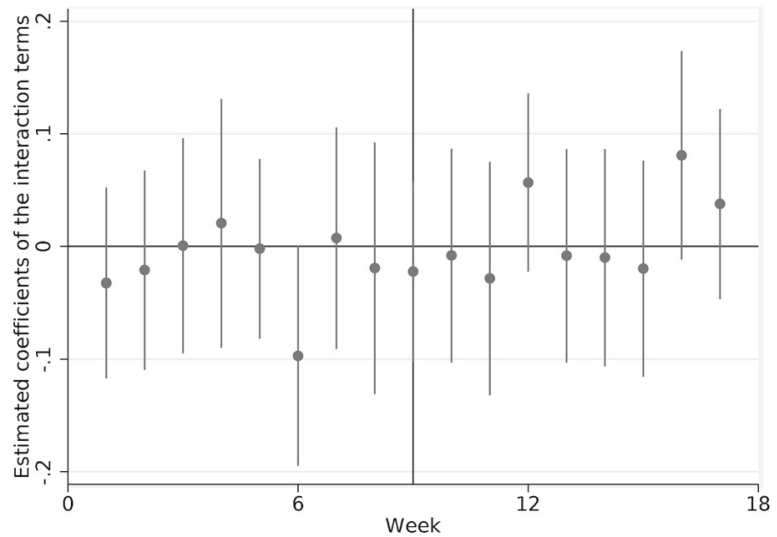

Fig. 3 Estimated coefficients, 95\% confidence intervals

\subsection{Robustness checks}

In the following, we report the estimation results of two further exercises aimed at assessing the robustness of our baseline results to different choices of the time window around the reform implementation and to the criteria applied to the sample selection based on firm size.

Our baseline results are based on a symmetric 18-week window starting January 3rd 2015. In Table 5 we report the estimation results based on different sample sizes, selected according to different widths of the time window. It is worth noticing that the choice of the window affects the magnitude of the estimated ATET but never gives rise to a negative and statistically significant treatment effect.

We also check whether choosing a different sample based on the firm size actually affects the results. The baseline model is estimated on a sample of contracts signed in firms with more than 6 employees. We left out contracts signed in micro enterprises in order to keep our sample somewhat homogeneous, avoiding potentially confounding factors that could systematically affect their labour demand dynamics. Looking at the results reported in Table 6, it is worth noticing that shrinking the sample size to contracts signed in firms between 11 and 20 employees and in firms between 6 and 50 employees returns an ATET that is not statistically significant. Instead, positive and statistically significant coefficients turn up if we consider contracts signed in small and medium firms (6-200) or if micro enterprises are included, thereby confirming the conjecture that the reform my have had heterogeneous effects according to the treated firms size. Lastly, we check whether the estimated causal effect is threatened by the endogeneity of firms size, as it might have been strategically increased (or decreased) before the policy implementation in order to exploit the reduction (or not) of firing costs for subsequent hirings (Boeri and Garibaldi 2019; Sestito and Viviano 2018). Because the information on firms size in our dataset refers to the average number of employees in 2014, this mechanism might have let us to wrongly assign firms to the treated or control group. Assuming that firms that endogenously cross the threshold 


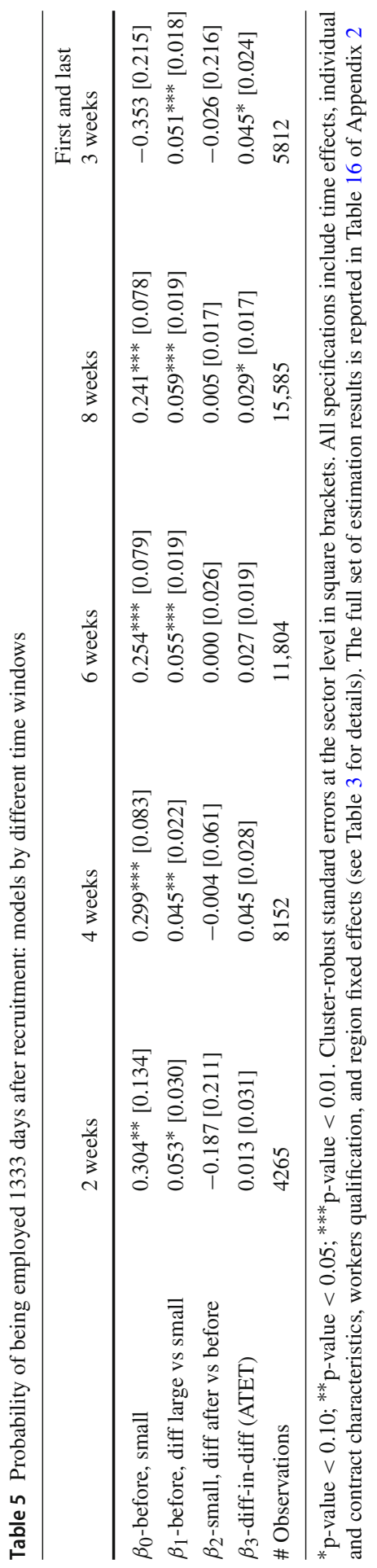


are those with a number of employees close to 15 , we check the robustness of our baseline result by excluding from the sample contracts signed in firms with 11 to 20 employees. The estimated ATET reported in the last column of Table 6 is in line with that or our baseline results.

Our final robustness exercises, reported in Table 7, concern other sample and model specification choices. First, we add to our set of covariates 1-digit sector fixed effects, which were excluded from our baseline specification because they do not refer to the pre-treatment period, but pertain to the records acquired in 2015. Because hirings may have been systematically higher in certain sectors during the months considered in the analysis, we check whether sector-specific effects may act as confounders and affect the estimated ATET; the results in the first column of Table 7 document that this is not the case.

Secondly, we include part time workers in the sample. As it is common practice in empirical labour economics, we left them out of our baseline analysis to keep the sample somewhat homogeneous, as part-timers can be subject to substantially different mechanisms than standard full-time permanent employment in many respects. However, the Jobs Act renewed the regulation for part-time work, by preventing the employer from unilaterally modifying the scheduling of working ours. Such a modification may have somehow changed the employer-employee relationship and it cannot be excluded that contract duration might be affected as a consequence. The estimation results in the second column of Table 7, where a dummy for part-timers is also included in the set of covariates, report a small but significant positive effect of the reduction of firing costs for this sample as well, thus implying that the slight increase in the job survival probability after the introduction of the new IPC is not the result of excluding part-time workers. Yet further inquiries on the mechanism through which the new IPC may have affected part-time work are beyond the scope of this paper.

\section{Discussion}

The results reported in Sect. 4 are somewhat puzzling: workers hired with the IPC are no more at risk of job termination than those hired under a stricter employment protection legislation. In fact, they even seem significantly more likely to be still employed after 1333 days. This finding is in contrast with the theoretical predictions, that would see workers hired with lower firing costs more at risk of contract termination. In this section, we investigate some potential mechanisms, depending on the firm recruitment strategy and workers motivation that may have given rise to this result jointly with the introduction of the new IPC.

\subsection{Resigning Versus Firing}

In the following we discuss a first set of hypotheses that deal with relative changes in layoffs and voluntary resignations upon the implementation of the new IPC. 


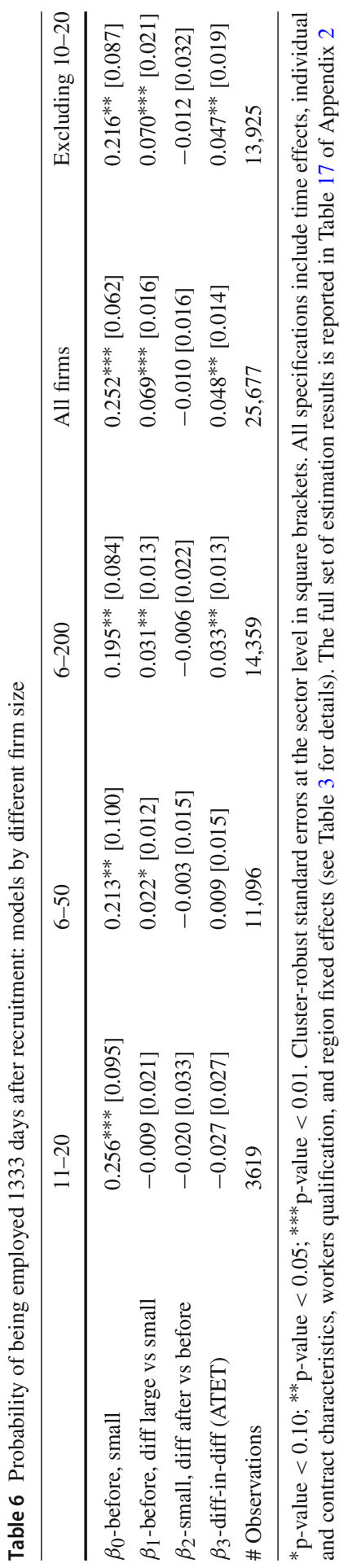


Table 7 Probability of being employed 1333 days after recruitment: models with sector fixed-effects and including part-time workers

\begin{tabular}{lll}
\hline & 1-digit sector FE & Part-time \\
\hline$\beta_{0}$-before, small & $0.307^{* * *}[0.073]$ & $0.175^{* * *}[0.061]$ \\
$\beta_{1}$-before, diff large vs small & $0.048^{* * *}[0.018]$ & $0.067^{* * *}[0.014]$ \\
$\beta_{2}$-small, diff after vs before & $-0.011[0.021]$ & $0.006[0.024]$ \\
$\beta_{3}$-diff-in-diff (ATET) & $0.028^{*}[0.014]$ & $0.025^{* *}[0.013]$ \\
$\#$ Observations & 16,914 & 25,759 \\
\hline
\end{tabular}

${ }^{*}$ p-value $<0.10 ;{ }^{* *}$ p-value $<0.05 ;{ }^{* * *}$ p-value $<0.01$. Cluster-robust standard errors at the sector level in square brackets. All specifications include time effects, individual and contract characteristics, workers qualification, and region fixed effects (see Table 3 for details). The full set of estimation results is reported in Table 18 of Appendix 2

Table 8 Sample frequency of layoffs and resignations before and after March 7th 2015 by firm size

\begin{tabular}{llll}
\hline & & Fired & Resigned \\
\hline Before & Small & 0.43 & 0.32 \\
Before & Large & 0.33 & 0.34 \\
After & Small & 0.46 & 0.33 \\
After & Large & 0.36 & 0.31 \\
Total & & 0.39 & 0.32 \\
\hline
\end{tabular}

\subsubsection{Resignations Compensating Layoffs}

Motivated by the recent empirical findings on firing rates (Boeri and Garibaldi 2019), it might be argued that no significant average treatment effects arise because a decrease in voluntary resignations could have compensated an increase in layoffs. This might occur because the reform also changed the modality of resignation, thereby limiting the practice of white resignations. Looking at the figures for our sample, firings increase by 3 percentage points in large firms, fully compensating the reduction in resignations, whereas in small firms both firings and resignations increase. (see Table 8).

We present further evidence in Table 9, where we report the estimation results relative to the average effects of the introduction of the new IPC on two outcome variables: the first (Not fired) is a binary variable taking value 1 if the worker is still employed 1333 days after recruitment or has resigned and 0 if the worker has been laid off; the second (Not resigned) is a binary variable taking value 1 if the worker is still employed 1333 days after recruitment or has been fired and 0 if the worker has resigned. ${ }^{9}$ If among the treated a higher firing rate has compensated a decrease in voluntary resignations, then we should observe a negative sign of the ATET in the first and a positive one in the second column of Table 9, but the results do not seem to support this assumption.

\footnotetext{
9 Building the dependent variable this way inevitably brings non-random sample selection. As it was suggested by a reviewer, however, this exercise still offers some descriptive evidence on whether voluntary resignations are driving the overall result on the effect of the new IPC.
} 
Table 9 Probability of not being fired and not resigning 1333 days after recruitment

\begin{tabular}{lll}
\hline & Not fired & Not resigned \\
\hline$\beta_{0}$-before, small & $0.929^{* * *}[0.063]$ & $0.309^{* * *}[0.077]$ \\
$\beta_{1}$-before, diff large vs small & $0.060^{* * *}[0.012]$ & $-0.004[0.017]$ \\
$\beta_{2}$-small, diff after vs before & $-0.008[0.014]$ & $-0.002[0.018]$ \\
$\beta_{3}$-diff-in-diff (ATET) & $0.011[0.015]$ & $0.022[0.016]$ \\
$\#$ Observations & 16,914 & 16,914 \\
\hline
\end{tabular}

${ }^{*}$ p-value $<0.10 ;{ }^{*}$ p-value $<0.05 ;{ }^{* * *}$-value $<0.01$. Cluster-robust standard errors at the sector level in square brackets. All specifications include time effects, individual and contract characteristics, workers qualification, and region fixed effects (see Table 3 for details). The full set of estimation results is reported in Table 19 of Appendix 2

\subsubsection{Voluntary Resignations in Small Firms}

Our results might also be driven by a second mechanism exerted by the reform on voluntary resignations and firings according to which, in times of labour market upturns, workers employed in small firms may prefer to look for a new job in larger firms, that typically offer higher wages and more opportunities to move up the ladder (Moscarini and Postel-Vinay 2012). Therefore, a similar mechanism can be expected to spur with the introduction of the new IPC, which made hirings more convenient for large firms.

Yet voluntary resignations increased only by $1 \%$ point after the reform (see Table 8) and both the estimated $\beta_{2}$ and $\beta_{3}$ in the second column of Table 9 are positive and not statistically significant (contrary to the expected statistically significant negative estimate of $\beta_{2}$ and positive estimate of $\beta_{3}$ ). It therefore emerges that voluntary resignations do not significantly depend on firms size nor on the period considered (pre/after the introduction of the IPC reform).

\subsection{Composition Effects Among the Treated}

A second set of hypotheses stem from potential composition effects among the treated workers. Large firms may have changed their recruitment policy after the introduction of the new IPC, recruiting workers that have a smaller probability of contract termination. In the following we investigate the case of workers hired with transformations of temporary contracts, workers eligible for the 3-year rebate on non-wage labour costs, and finally "riskier" workers, who may have been more convenient for large firms after the reform (Kugler and Saint-Paul 2004).

\subsubsection{Transformation of Temporary Contracts}

A first composition effect can be the result of an increased convenience for large firms to substitute temporary contracts with the new IPC. As argued by Sestito and Viviano (2018), it is common practice for firms to first hire workers with a temporary contract to screen them and then convert their contracts into permanent ones. Clearly, the higher the firing costs, the more convenient this two-step strategy is for firms. Therefore, 
after the reduction of firing costs, firms may have substituted temporary positions with permanent ones even if the working relationship was set to last a fixed amount of time $\tau$. If this is the case, we should then observe a reduction in terminations of permanent contracts before $\tau$, possibly followed by an increase in separations after $\tau$. Therefore, an estimated non-negative ATET could actually be the result of $\tau>1333$ days.

An increase in the transformation of temporary contracts into permanent ones may also give rise to a composition effect. Large firms that intend to transform temporary positions into permanent ones may find it more convenient to do so after the introduction of the IPC. This way, the firm is able to subscribe a contract with lower firing costs than the old one and to exploit the rebate on non-wage labour costs that goes with new permanent positions, where applicable. We provide a simple theoretical framework explaining this mechanism in Sect. 1 of Appendix 1. In addition, if the firm transforms the temporary positions of only more productive workers, then we could find a positive ATET, as these workers should have a higher probability of still being employed 1333 days after recruitment. Indeed, in our data permanent workers hired with a transformation of a temporary contract do have on average a higher survival probability $(77 \%)$ than those recruited with all-new permanent positions $(60 \%)$. This also emerges from the estimation results in Table 14 in Appendix 2, where the coefficient associated to the binary variable for the contract transformation is positive and statistically significant in all the specifications considered.

Table 10 reports estimation results from some exercises aimed at investigating these possibilities. The results in the first column refer to a model where the outcome is a dummy variable equal to 1 if the worker is hired with a permanent contract as a result of a transformation of a temporary one and equal to 0 otherwise. It emerges that large firms are more likely to transform temporary contracts before the reform and that this probability increases for all firms after the introduction of the IPC, but with no significant treatment effect. The second and third column report the estimation results for the probability of being employed 1333 days after recruitment separately for transformed and new contracts. The results detect some heterogeneity, although slightly significant, in the likelihood of still being employed after 1333 days for workers with a transformed position after the reform in large firms with respect to those hired directly with the new IPC, which could be linked to the higher survival rate that characterises previously screened workers.

\subsubsection{The Combined Effect of Reducing Firing and Non-wage Labour Costs}

We also look into the possibility that our findings are driven by the combined effect of the introduction of the IPC and of the hiring incentive on non-wage labour costs. It may be argued that the arbitrariness of court decisions and the risk of reinstatement before the IPC reform might have limited large firms willingness to hire on a permanent basis. The introduction of the incentive may have increased per se large firms propensity to hire permanent workers and the introduction of the IPC to postpone recruitment until after the reduction of firing costs was implemented. The simple theoretical framework in Sect. 1 in Appendix 1 provides a formalised explanation. This mechanism can result in a non-negative estimated ATET if large companies had waited for the introduction 


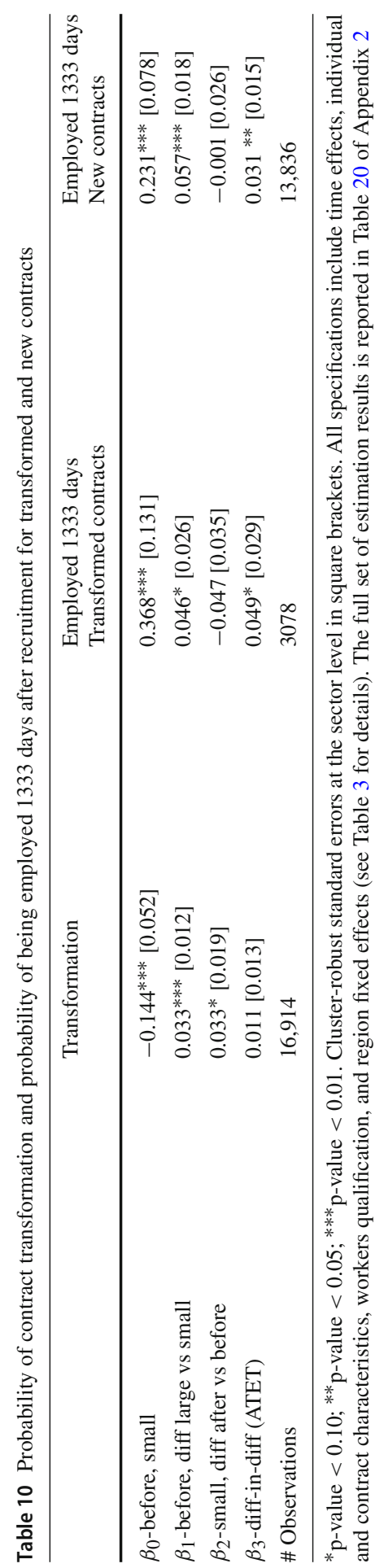


of the IPC before hiring highly productive workers. In fact, workers hired with incentivised contracts have a survival probability of $56 \%$, against $38 \%$ of non-incentivised workers. Moreover, the former exhibit a significantly higher survival probability other things being equal as well (see Table 14 in Appendix 2).

The results reported in the first column in Table 11 refer to a model where the outcome is a binary variable equal to 1 if the worker is hired with the incentive and equal to 0 otherwise. It actually emerges that large firms are more likely to hire workers using the incentive after the introduction of the IPC with respect to small firms, but the related ATET is only mildly statistically significant. On this basis, we cannot ascribe the non-negative estimated ATET to a significantly higher share of eligible workers hired after the reform. Also, the second and third column report the estimation results for the probability of still being employed 1333 days after recruitment separately for workers hired with non-incentivised and incentivised contracts, and no significant differences in the ATET emerge.

\subsubsection{The Hiring of Risky Workers}

We last look into the possibility that the reduction of firing costs may have pushed firms to hire what we call risky workers (Lazear 1995; Kugler and Saint-Paul 2004; Sestito and Viviano 2018), that are those with a more volatile productivity distribution. In a reverse context, Kugler and Saint-Paul (2004) showed that a stricter employment protection legislation favours the hiring of screened workers, such as those who are already employed and are therefore less likely to be lemons. If this mechanism is put in motion by the reduction of firing costs brought by the reform, in presence of a negative shock in the short run workers with low productivity are rapidly screened and more at risk of job termination. However, in the medium-run, the remaining new workers may have a higher productivity level than employees under the old firing rules and, therefore, have a higher survival probability.

We provide a tentative theoretical explanation of this rationale in Sect. 2 of Appendix 1 and we attempt to find some descriptive evidence in our data that firms with 15 employees or more have a higher propensity to recruit risky workers after March 7th 2015, by characterising risky workers as those less than 37 years old and hired with a contract that is not a result of a transformation. The first column of Table 12 reports the results for the probability of hiring risky workers. It emerges that large firms have a higher propensity to recruit young and previously unknown workers after the reform than before, as opposed to small firms. Also, estimates carried out separately for risky and non risky workers do point toward different estimated ATET on the probability of being employed 1333 days after recruitment: risky workers exhibit a significantly higher survival probability, compared to non risky ones, in large firms after the reform with respect to those hired in small firms.

Finally, some evidence of a selection mechanism taking place in the short run could be provided by Table 13, where we report estimation results for different definitions of the response variable. In particular, we evaluate the effect of the new IPC on the probability of still being employed 13, 26, 52, and 104 weeks after recruitment, corresponding to $91,182,364$, and 628 days respectively. Results show that after approximately 3 months since signing the contract, the ATET is negative and mildly 


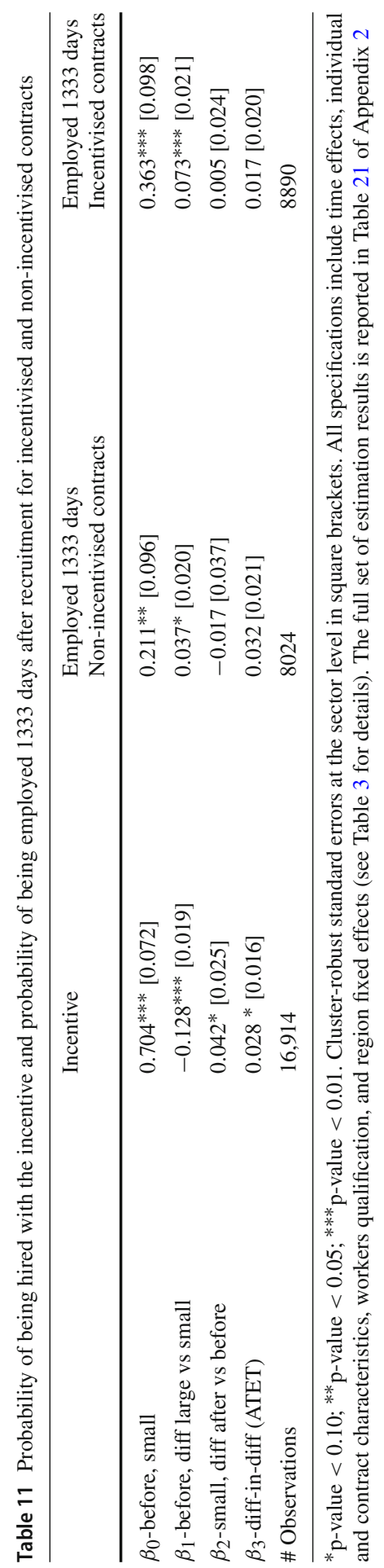


Table 12 Probability of hiring risky workers and probability of being employed 1333 days after recruitment for risky and not risky workers

\begin{tabular}{llll}
\hline & Risky & $\begin{array}{l}\text { Employed 1333 days } \\
\text { Risky }\end{array}$ & $\begin{array}{l}\text { Employed 1333 days } \\
\text { Not risky }\end{array}$ \\
\hline$\beta_{0}$-before, small & $0.313^{* * *}[0.024]$ & $0.341^{* * *}[0.041]$ & $0.356^{* * *}[0.038]$ \\
$\beta_{1}$-before, diff large vs small & $0.004[0.012]$ & $0.053^{* *}[0.025]$ & $0.060^{* * *}[0.017]$ \\
$\beta_{2}$-small, diff after vs before & $-0.002[0.019]$ & $0.004[0.028]$ & $-0.018[0.031]$ \\
$\beta_{3}$-diff-in-diff (ATET) & $0.040^{* * *}[0.015]$ & $0.052^{* *}[0.022]$ & $0.032[0.020]$ \\
$\#$ Observations & 16,914 & 5394 & 11,520 \\
\hline
\end{tabular}

${ }^{*}$ p-value $<0.10 ;{ }^{* *}$-value $<0.05 ; * *$ p-value $<0.01$. Cluster-robust standard errors at the sector level in square brackets. All specifications include workers gender, workers qualification, contract characteristics, and region fixed effects. (see Table 3 for details). The full set of estimation results is reported in Table 22 of Appendix 2

Table 13 Probability of being employed 13, 26, 52, and 104 weeks after recruitment

\begin{tabular}{lllll}
\hline & 13 & 26 & 52 & 104 \\
\hline$\beta_{0}$-before, small & $0.837 * * *[0.040]$ & $0.677^{* * *}[0.059]$ & $0.536 * * *[0.082]$ & $0.357 * * *[0.075]$ \\
$\beta_{1}$-before, diff large vs small & $0.037 * * *[0.009]$ & $0.047 * * *[0.011]$ & $0.050 * * *[0.013]$ & $0.059 * * *[0.013]$ \\
$\beta_{2}$-small, diff after vs before & $0.021[0.017]$ & $0.050^{* *}[0.020]$ & $0.011[0.021]$ & $0.023[0.022]$ \\
$\beta_{3}$-diff-in-diff (ATET) & $-0.017 *[0.010]$ & $-0.013[0.014]$ & $0.032 * *[0.014]$ & $0.025 *[0.013]$ \\
\# Observations & 16,914 & 16,914 & 16,914 & 16,914 \\
\hline
\end{tabular}

${ }^{*}$ p-value $<0.10 ;{ }^{* *}$-value $<0.05 ;{ }^{* * *}$-value $<0.01$. Cluster-robust standard errors at the sector level in square brackets. All specifications include workers gender, workers qualification, contract characteristics, and region fixed effects. (see Table 3 for details). The full set of estimation results is reported in Table 23 of Appendix 2

statistically significant. It then turns positive and increases as time passes. It might be conjectured that if employers choose to terminate some contracts, they would do so in the short run when it is more convenient with the new IPC. Moreover, because of the rebate on non-wage labour costs, it stands to reason that only very bad matches would be terminated. We however refrain to draw any conclusion based on these results as it is not possible, with the data at hand, to identify the motivation for dismissals, nor the results for the probability of not being fired and not resigning for the same time horizons offered conclusive evidence in this respect (estimation results are available upon request).

\section{Conclusions}

Law no. 183, of December 20th 2014, generally known as the Jobs Act, defined the new IPC for permanent workers, that removes the possibility of reinstatement in case of dismissal without a just cause and sensibly reduced firing costs. It is common sense that this reform has made the Italian labour market more flexible, encouraged companies to increase their recruitment with open-ended contracts and generated more precarious 
and unstable jobs for workers hired after the reform. Extant empirical evidence seems to confirm this common feeling: the reform raised turnover, so that both hirings and separations increased.

In this paper, we attempt an evaluation of whether this higher turnover actually affected workers recruited after the reform. This could be expected on the basis of theoretical predictions, both because workers hired after the reform should be less productive and job termination, to which they should be more exposed, is less expensive to the firm. Contrary to the expected, our results show that workers hired under the new firing rules show, on average, the same probability of contract termination 1333 days after the job started as untreated workers or, in some cases, the probability of still being employed is a few percentage points significantly higher.

We attempt several empirical tests aimed to find rationales for this result, based on differences in voluntary resignations and firings and on composition effects, which may have entailed an increase of hired permanent workers with a larger job survival probability in large firms after the reform. Our results suggest that firms have moved towards the recruitment of riskier workers, probably younger and with no previous experience, that have a more volatile productivity distribution and are more at risk of job termination. If, right after hiring, firms have a screening process in place, less productive workers are rapidly dismissed if they are discovered to be "lemons" or in case of an adverse shock. In the medium run, however, the remaining treated workers may be preferred to those hired under the old firing rules and, therefore, may be less at risk of job termination in presence of a negative shock.

Whether the recruitment strategy represents the driver to this result requires further research based on a longer period of observation of the different categories of workers coexisting in the Italian labour market.

Funding Open access funding provided by Università Politecnica delle Marche within the CRUI-CARE Agreement.

Open Access This article is licensed under a Creative Commons Attribution 4.0 International License, which permits use, sharing, adaptation, distribution and reproduction in any medium or format, as long as you give appropriate credit to the original author(s) and the source, provide a link to the Creative Commons licence, and indicate if changes were made. The images or other third party material in this article are included in the article's Creative Commons licence, unless indicated otherwise in a credit line to the material. If material is not included in the article's Creative Commons licence and your intended use is not permitted by statutory regulation or exceeds the permitted use, you will need to obtain permission directly from the copyright holder. To view a copy of this licence, visit http://creativecommons.org/licenses/by/4.0/.

\section{Theoretical Underpinnings}

\section{Composition Effects Due to Transformations of Temporary Contracts or to a Reduction of Non-wage Labour Costs}

In the following, we provide a simple theoretical framework explaining why large firms may have increase recruitment in the form of transformation of temporary contracts and/or higher workers eligible for the incentive in non-wage labour costs. Consider a firm that must decide whether to offer (or to continue) a temporary contract or to open 
a permanent position (or to transform an existing temporary contract into a permanent one). The asset value of a temporary contract $J^{T}$ can be written as

$$
J^{T}=y-w^{T}+\frac{(1-\lambda)(1-\phi) J^{T}}{1+r} \quad \rightarrow \quad r J^{T}=\frac{1+r}{r+\lambda+\phi-\lambda \phi}\left(y-w^{T}\right),
$$

where $y$ and $w^{T}$ are production and wage rate in the temporary position, respectively, $\lambda$ is the exogenous probability of a shock terminating the job, $\phi$ is the probability that the worker finds another job (assuming that temporary workers look for better job opportunities) and $r$ is the discount rate. In the case of a shock or voluntary resignation, the value of the job is assumed to be equal to zero. The asset value of a permanent contract $J^{P}$ can be written as

$$
J^{P}=y-w^{P}+\frac{(1-\lambda) J^{P}-\lambda F}{1+r} \rightarrow r J^{P}=\frac{1+r}{r+\lambda}\left(y-w^{P}\right)-\lambda F,
$$

where $F$ represent the firing costs and $w^{P}$ is the wage in the permanent position.

Firms would prefer to recruit less expensive permanent workers but high firing costs may prevent them from doing so. The condition to prefer the permanent position over the temporary one, $J^{P}>J^{T}$, becomes:

$$
\frac{1+r}{r+\lambda}\left(y-w^{P}\right)-\lambda F>\frac{1+r}{r+\lambda}\left(y-w^{T}\right),
$$

and can be re-written as

$$
\left(w^{T}-w^{P}\right)(r+\lambda)+\phi(1-\lambda)\left(y-w^{P}\right)>\frac{r+\lambda+\phi(1-\lambda)}{1+r} \lambda F .
$$

The above inequality is more likely to hold if the wage rate of temporary workers is higher than for permanent ones, which is true if workers are eligible for the subside, if temporary workers easily find a new job position (large are $\phi$ ), and if a high profit is generated in the permanent position (large $y-w^{P}$ ). A reduction in firing costs, such as the one produced by the reform, makes it more convenient to hire workers eligible for the incentive and to transform the "best" temporary workers, i.e. those who would easily find another job and generate a higher profit. Since the former are less expensive and the latter may be more productive, they can both be at a lesser risk of job termination compared to workers hired with the old permanent contract.

\section{The Hiring of Risky Workers}

Here we present a simple theoretical framework describing a setting where the recruitment of two types of workers is considered: experienced or inexperienced. We assume that the productivity of an experienced worker can be perfectly predicted by the firm and the worker is fired only in the event of a negative shock. Conversely, the productivity of an inexperienced worker can be hardly predicted and the worker can be fired 
even as a result of a bad quality of the match. The aim of the model is therefore to pin down the relationship between firing costs and the willingness to recruit inexperienced workers.

A match with an experienced worker ends up with a perfectly predictable productivity level, say $\bar{y}$. A match with an inexperienced worker can instead turn out to be Good, with a productivity equal to $y^{G}$, or Bad, with $y^{B}$, with $y^{B}<\bar{y}<y^{G}$. Let $q$ be the expected share of good matches when hiring inexperienced workers and we assume that $\bar{y}=q y^{G}+(1-q) y^{B}$, so that, on average, the two types of workers have the same expected productivity.

Assuming that the value of a vacancy is zero, the expected profit from an experienced worker is

$$
\Pi^{E}=\bar{y}-w+\frac{(1-\lambda) \Pi^{E}+\lambda(-F)}{1+r} \rightarrow \Pi^{E}=\frac{1+r}{r+\lambda}(\bar{y}-w)-\frac{\lambda}{r+\lambda} F,
$$

where $w$ is the wage, $r$ the discount factor, $\lambda$ is the exogenous probability of a negative shock that destroys the job position, and $F$ are the firing costs.

The expected profit from an inexperienced worker takes into account the productivity uncertainty, which is unknown at the time of the recruitment and observable only at the end of the first period. If the match turns out to be bad, the inexperienced worker will be fired and a vacancy for another inexperienced worker open up. Instead, if the match turns out to be a good one, the working relationship will continue unless negative shocks occur. Because a good match entails a higher productivity, we assume that good matches with inexperienced workers give rise to a probability of job termination, due to a negative shock, equal to $\mu \lambda$, with $\mu<1$. Therefore, the expected profit from an inexperienced worker is

$$
\begin{aligned}
& \Pi^{U}=\bar{y}-w+\frac{(1-q)\left(\Pi^{U}-F\right)+q \Pi^{U G}}{1+r} \\
& \rightarrow \Pi^{U}=\frac{(1+r)(\bar{y}-w)+q \Pi^{U G}-(1-q) F}{r+q}
\end{aligned}
$$

where $\Pi^{U G}$ is the expected profit from good matches with inexperienced workers, given by

$$
\Pi^{U G}=y^{G}-w+\frac{(1-\mu \lambda) \Pi^{U G}-\mu \lambda F}{1+r}, \quad \rightarrow \quad \Pi^{U G}=\frac{\left(y^{G}-w\right)(1+r)-\mu \lambda F}{r+\mu \lambda} .
$$

Substituting $\Pi^{U G}$ in (3), we obtain

$$
\Pi^{U}=\frac{1+r}{r+q}\left[(\bar{y}-w)+\frac{q}{r+\mu \lambda}\left(y^{G}-w\right)\right]-\frac{r(1-q)+\mu \lambda}{(r+\mu \lambda)(r+q)} F .
$$


The condition required to make the hiring of risky workers the best strategy is $\Pi^{U} \geq \Pi^{E}$. This condition can be written as

$$
\begin{aligned}
& (1+r)[(r+\mu \lambda)(\lambda-q)(\bar{y}-w)]+(r+q) q\left(y^{G}-w\right) \\
& \geq[(r+\lambda)[r(1-q)+\mu \lambda]-\lambda(r+\mu \lambda)(r+q)] F
\end{aligned}
$$

and, solved in firing costs $F$, we obtain ${ }^{10}$

$$
F<(1+r) \frac{(r+\mu \lambda)(\lambda-q)(\bar{y}-w)+(r+q) q\left(y^{G}-w\right)}{(r+\lambda)[r(1-q)+\mu \lambda]-\lambda(r+\mu \lambda)(r+q)} \equiv \bar{F}>0 .
$$

Now assume that, because of the treatment, $F$ reduces from $F_{0}>\bar{F}$ to $F_{1}<\bar{F}$ for a given share, say a half for simplicity, of the new vacancies. Both experienced and inexperienced workers are hired in treated firms at time 0 . Given that a negative shock hits a share of experienced workers equal to $\lambda$, the same share $\lambda$ of workers is fired in the first period. Among the inexperienced workers, a share $(1-q)+q \mu \lambda$ is fired, that are all the bad matches and a share $\mu \lambda$ of the good ones. As a consequence, in the first period the termination rate is lower for experienced workers if $\lambda<1-q(1-\mu \lambda)$.

In the second period, a share $(1-\lambda)$ of the experienced and a share $1-[q \mu \lambda+$ $(1-q)]=q(1-\mu \lambda)$ of the inexperienced workers are still employed. In the period $t$, the survival probability of experienced workers $\left(S_{t}^{E}\right)$ is given by:

$$
S_{t}^{E}=(1-\lambda)^{t}
$$

where the same figure for the inexperienced workers is:

$$
S_{t}^{U}=q(1-\mu \lambda)^{t}
$$

Inexperienced workers turn out to show a higher survival rate if $S_{t}^{U}>S_{t}^{E}$, that is

$$
q(1-\mu \lambda)^{t}>(1-\lambda)^{t} \rightarrow q>\left(\frac{1-\lambda}{1-\mu \lambda}\right)^{t}
$$

Given $\mu<1$, the rhs decreases over time whereas the lhs remains constant. Therefore, at some time $t$, inexperienced workers hired at time 0 will have a higher survival rate than the experienced ones.

If the share of good matches among inexperienced workers is below a given threshold (see the footnote 10), the model implication is twofold: a reduction in firing costs increases the likelihood of hiring inexperienced workers; the survival probability for

\footnotetext{
10 We assume that the condition $(r+\lambda)[r(1-q)+\mu \lambda]-\lambda(r+\mu \lambda)(r+q)>0$ is satisfied. It requires $q<\frac{\lambda+r(1-\lambda)}{\lambda+r \frac{r+\lambda}{r+\mu \lambda}}$ that is, the share of good workers should be lower than a critical value. Obviously, with a very high share of good workers among the inexperienced ones, the optimal strategy is to always hire inexperienced workers.
} 
Table 14 Probability of being employed 1333 days after recruitment

\begin{tabular}{|c|c|c|c|c|}
\hline & (1) & (2) & (3) & (4) \\
\hline$\beta_{0}$-before, small & $0.435 * * *[0.032]$ & $0.505 * * *[0.027]$ & ] $0.168 * *[0.079]$ & $0.238 * * *[0.077]$ \\
\hline$\beta_{1}$-before, diff large vs small & $0.058 * *[0.022]$ & $0.044 * *[0.022]$ & $0.064 * * *[0.016]$ & $0.056^{* * *}[0.017]$ \\
\hline$\beta_{2}$-small, diff after vs before & $-0.040 * * *[0.012]$ & ] $0.014[0.027]$ & $-0.029 * *[0.011]$ & $-0.010[0.023]$ \\
\hline$\beta_{3}$-diff-in-diff (ATET) & $0.066 * * *[0.015]$ & $0.056 * * *[0.015]$ & ] $0.039 * * *[0.014]$ & $0.033 * *[0.014]$ \\
\hline Woman & & & $0.046 * * *[0.017]$ & $0.043 * * *[0.016]$ \\
\hline Age & & & $0.005[0.003]$ & $0.005[0.003]$ \\
\hline $\operatorname{Age}^{2}$ & & & $-0.000 * * *[0.000]$ & ]$-0.000 * * *[0.000]$ \\
\hline Tenure & & & $0.010 * * *[0.003]$ & $0.010 * * *[0.003]$ \\
\hline Experience & & & $0.012 * * *[0.001]$ & $0.011 * * *[0.001]$ \\
\hline Incentive & & & $0.138 * * *[0.019]$ & $0.133 * * *[0.018]$ \\
\hline Transformed & & & $0.190 * * *[0.011]$ & $0.193 * * *[0.012]$ \\
\hline Qualification (Ref: blue collar) & & & Ref. & Ref. \\
\hline White collar & & & $0.161 * * *[0.049]$ & $0.183 * * *[0.054]$ \\
\hline Middle manager & & & $0.131 * * *[0.018]$ & $0.122 * * *[0.019]$ \\
\hline Other & & & $0.158 * * *[0.042]$ & $0.145^{* * * *}[0.041]$ \\
\hline \# Observations & 16,914 & 16,914 & 16,914 & 16,914 \\
\hline Time effects & No & Yes & No & Yes \\
\hline Region of residence & No & No & Yes & Yes \\
\hline
\end{tabular}

Full estimates for Table 3

${ }^{*}$ p-value $<0.10 ;{ }^{* *}$ p-value $<0.05 ;{ }^{* * *}$ p-value $<0.01$. Cluster-robust standard errors at the sector level in square brackets. Time effects in specifications (2) and (4) include intercepts for the day of the week and the day of the month. Specifications (3) and (4) also include 19 region fixed effects

these workers is lower right after the recruitment, with respect to that of experienced workers, and higher in the medium run. ${ }^{11}$

\section{Full Set of Estimation Results}

See Tables 14, 15, 16, 17, 18, 19, 20, 21, 22 and 23.

\footnotetext{
11 A corollary of the model is that the reduction in firing costs should improve the productivity of the match in the long run.
} 
Table 15 Probability of being employed 1333 days after recruitment: placebo tests

\begin{tabular}{lll}
\hline & $\begin{array}{l}2014 / 1 / 3-2014 / 3 / 6 \\
2015 / 3 / 7-2015 / 5 / 8 \\
\end{array}$ & $\begin{array}{l}2014 / 1 / 3-2014 / 3 / 6 \\
2014 / 3 / 7-2014 / 5 / 8 \\
(1)\end{array}$ \\
\hline$\beta_{0}$-before, small & $0.098[0.081]$ & $0.066[0.106]$ \\
$\beta_{1}$-before, diff large vs small & $0.068^{* * *[0.020]}$ & $0.072 * * *[0.019]$ \\
$\beta_{2}$-small, diff after vs before & $0.022[0.025]$ & $0.007[0.029]$ \\
$\beta_{3}$-diff-in-diff (ATET) & $0.020[0.025]$ & $-0.008[0.024]$ \\
Woman & $0.044 *[0.017]$ & $0.058 * * *[0.018]$ \\
Age & $0.006^{* *}[0.003]$ & $0.003[0.003]$ \\
Age ${ }^{2}$ & $-0.000 * * *[0.000]$ & $-0.000 *[0.000]$ \\
Tenure & $0.012 * * *[0.002]$ & $0.020 * * *[0.004]$ \\
\hline
\end{tabular}

Table 15 continued

$2014 / 1 / 3-2014 / 3 / 6$

$2015 / 3 / 7-2015 / 5 / 8$

(1)

$0.010 * * *[0.001]$
$0.117 * * *[0.021]$
$0.173 * * *[0.014]$

Ref.

$0.261 * * *[0.075]$

$0.138 * * *[0.018]$

$0.219 * * *[0.043]$

14,004
2014/1/3-2014/3/6 2014/3/7-2014/5/8

(2)

$0.010 * * *[0.001]$

$0.096 * * *$ [0.020]

$0.120 * * *$ [0.020]

Ref.

0.098 [0.180]

$0.172 * * *$ [0.019]

$0.214 * * *[0.045]$

10,414

\# Observations

Full estimates for Table 4

${ }^{*}$ p-value $<0.10 ;{ }^{* *} \mathrm{p}$-value $<0.05 ;{ }^{* * *} \mathrm{p}$-value $<0.01$. Cluster-robust standard errors at the sector level in square brackets. Both specifications include time effects, individual and contract characteristics, workers qualification, and region fixed effects (see Table 3 for details) 


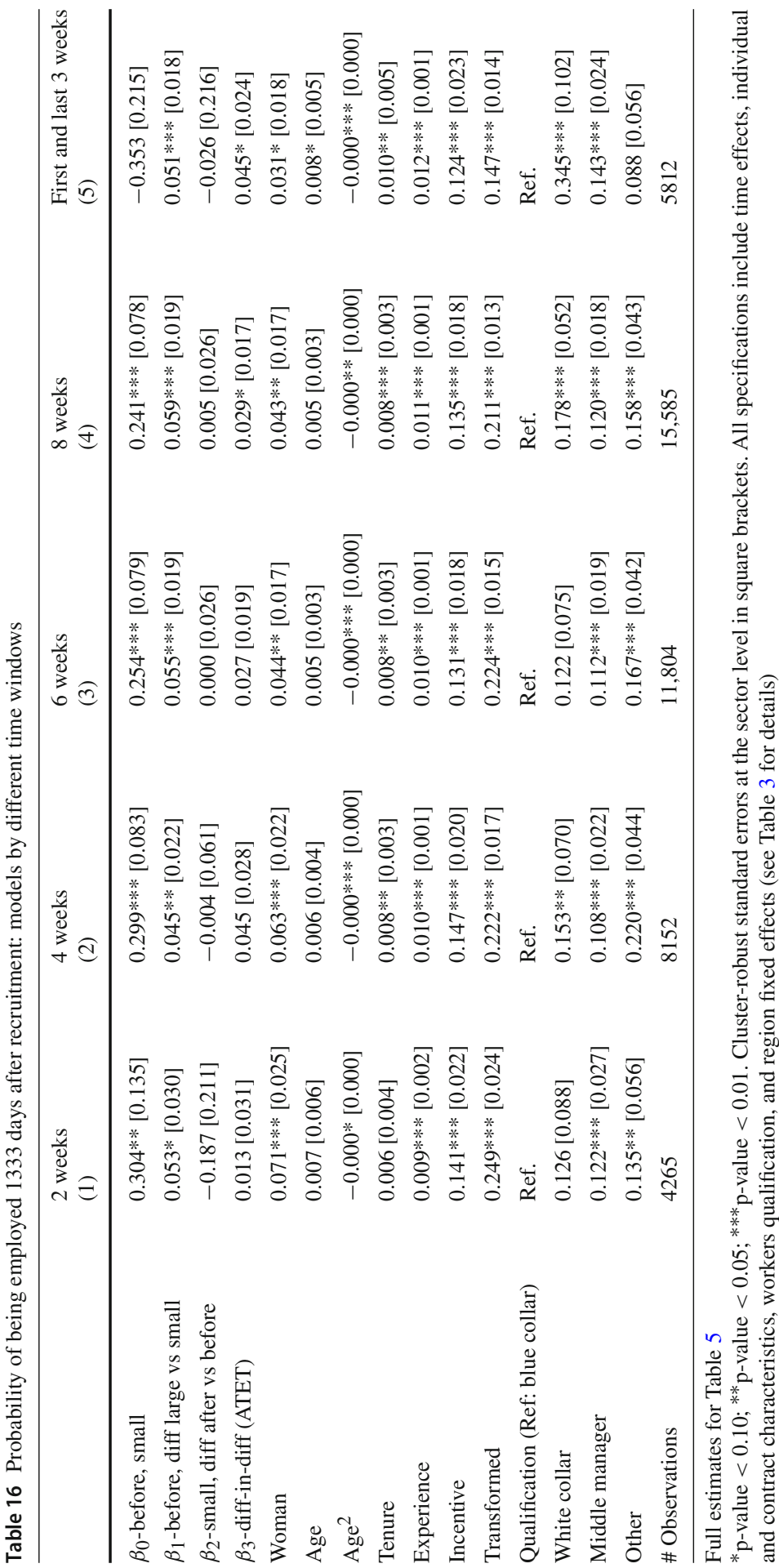




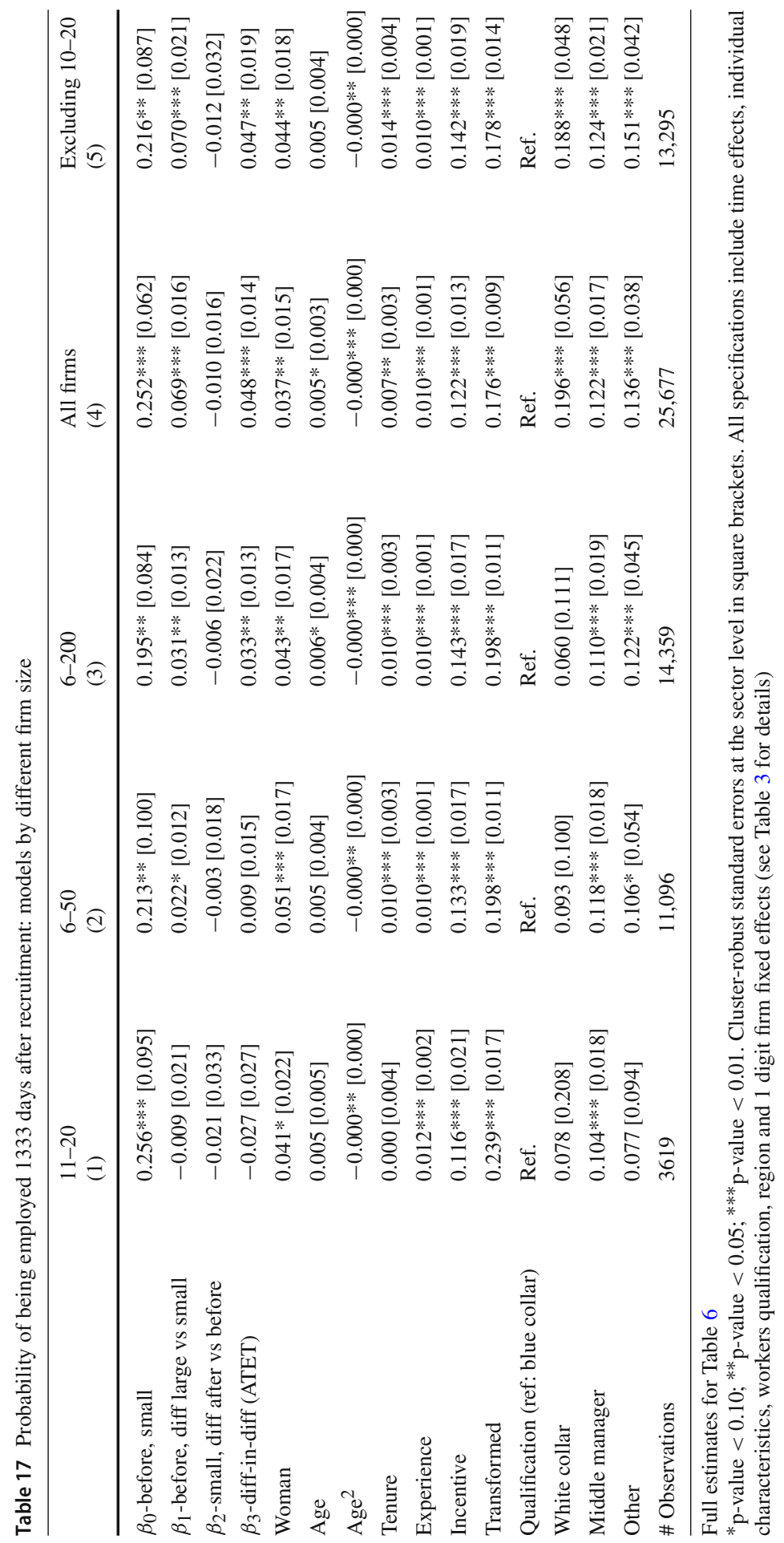


Table 18 Probability of being employed 1333 days after recruitment: models with sector fixed-effects and including part-time workers

\section{1-digit sector FE}

(1)

$\beta_{0}$-before, small

$\beta_{1}$-before, diff large vs small

$\beta_{2}$-small, diff after vs before

$\beta_{3}$-diff-in-diff (ATET)

Woman

Age

Age $^{2}$

Tenure

Experience

Incentive

Transformed

Qualification (Ref: blue collar)

White collar

Middle manager

Other

Part-time

\# Observations

$\begin{array}{ll}0.307 * * *[0.073] & 0.175 * * *[0.061] \\ 0.048 * * *[0.018] & 0.067 * * *[0.014] \\ -0.011[0.022] & 0.006[0.024] \\ 0.028 *[0.014] & 0.025 * *[0.013] \\ 0.038 * * *[0.013] & 0.034 * *[0.013] \\ 0.005[0.003] & 0.007 * * *[0.002] \\ -0.000 * * *[0.000] & -0.000 * * *[0.000] \\ 0.011 * * *[0.003] & 0.011 * * *[0.003] \\ 0.010 * * *[0.001] & 0.010 * * *[0.001] \\ 0.127 * * *[0.016] & 0.124 * * *[0.016] \\ 0.195 * * *[0.012] & 0.193 * * *[0.010] \\ \text { Ref. } & \text { Ref. } \\ 0.214 * * *[0.058] & 0.175 * *[0.058] \\ 0.116 * * *[0.018] & 0.127 * * *[0.014] \\ 0.123 * * *[0.038] & 0.142 * * *[0.039] \\ 16,914 & -0.004[0.019] \\ & 25,759\end{array}$

Full estimates for Table 7

${ }^{*}$ p-value $<0.10 ;{ }^{* *}$ p-value $<0.05 ;{ }^{* * *}$ p-value $<0.01$. Cluster-robust standard errors at the sector level in square brackets. All specifications include time effects, individual and contract characteristics, workers qualification, and region fixed effects (see Table 3 for details)
Part-time

(2)

at


Table 19 Probability of not being fired and not resigning 1333 days after recruitment

\begin{tabular}{|c|c|c|}
\hline & $\begin{array}{l}\text { Not fired } \\
\text { (1) }\end{array}$ & $\begin{array}{l}\text { Not resigned } \\
\text { (2) }\end{array}$ \\
\hline$\beta_{0}$-before, small & $0.929 * * *[0.063]$ & $0.309 * * *[0.077]$ \\
\hline$\beta_{1}$-before, diff large vs small & $0.060 * * *[0.012]$ & $-0.004[0.017]$ \\
\hline$\beta_{2}$-small, diff after vs before & $-0.008[0.014]$ & $-0.002[0.018]$ \\
\hline$\beta_{3}$-diff-in-diff (ATET) & $0.011[0.015]$ & $0.022[0.016]$ \\
\hline Woman & $0.009[0.017]$ & $0.034 * * *[0.011]$ \\
\hline Age & $-0.007 * * *[0.002]$ & $0.012 * * *[0.003]$ \\
\hline $\operatorname{Age}^{2}$ & $0.000[0.000]$ & $-0.000 * * *[0.000]$ \\
\hline Tenure & $-0.008 * *[0.003]$ & $0.018 * * *[0.002]$ \\
\hline Experience & $0.005 * * *[0.001]$ & $0.006 * * *[0.001]$ \\
\hline Incentive & $0.065 * * *[0.021]$ & $0.068 * * *[0.018]$ \\
\hline Transformed & $0.074 * * *[0.010]$ & $0.120 * * *[0.013]$ \\
\hline Qualification (Ref: blue collar) & Ref. & Ref. \\
\hline White collar & $0.107[0.103]$ & $0.076[0.066]$ \\
\hline Middle manager & $0.093 * * *[0.020]$ & $0.028[0.019]$ \\
\hline Other & $0.131 * * *[0.034]$ & $0.014[0.035]$ \\
\hline \# Observations & 16,914 & 16,914 \\
\hline
\end{tabular}

Full estimates for Table 9

${ }^{*}$ p-value $<0.10 ;{ }^{* *}$ p-value $<0.05 ;{ }^{* * *}$-value $<0.01$. Cluster-robust standard errors at the sector level in square brackets. All specifications include time effects, individual and contract characteristics, workers qualification, and region fixed effects (see Table 3 for details) 


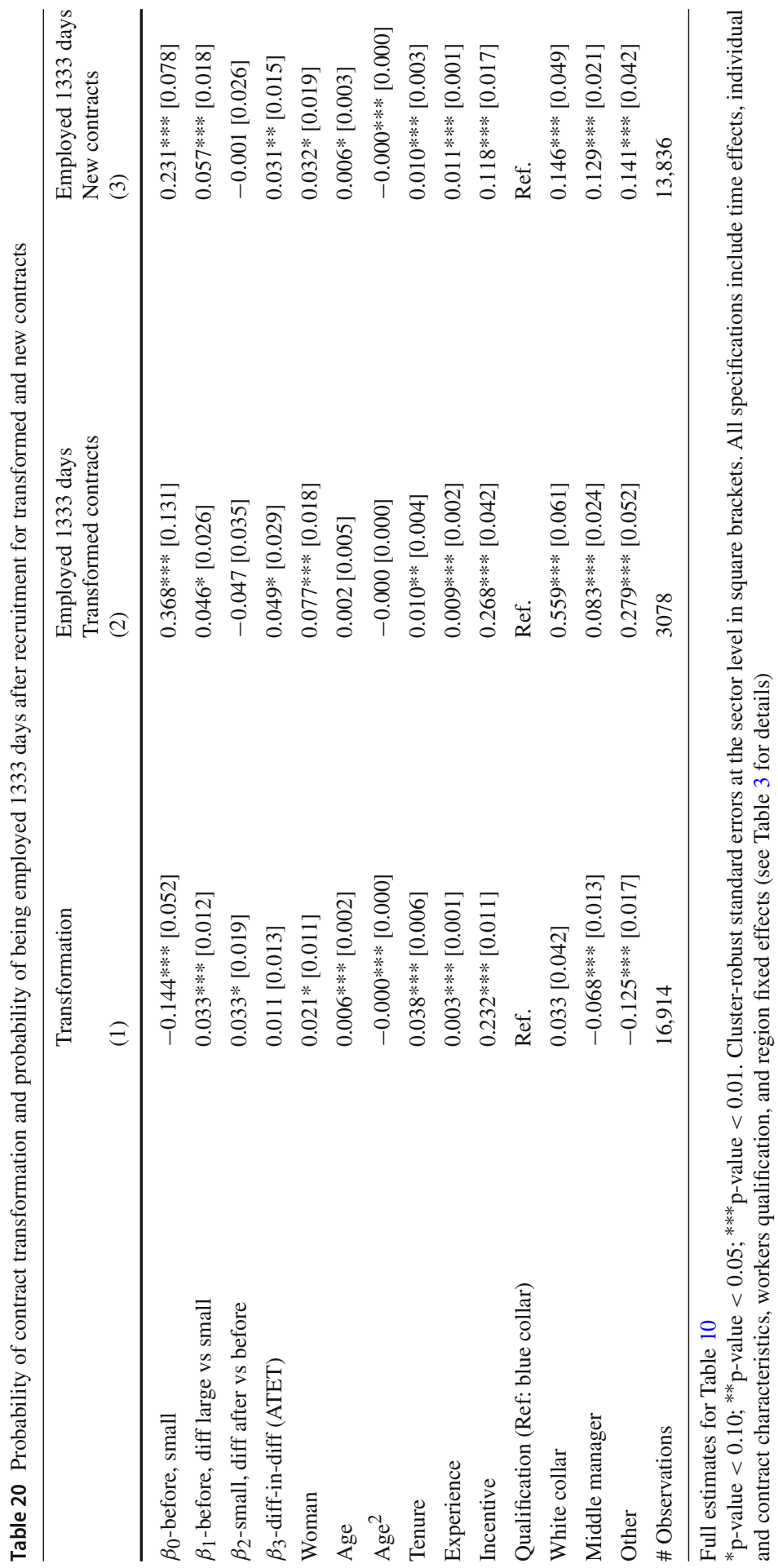




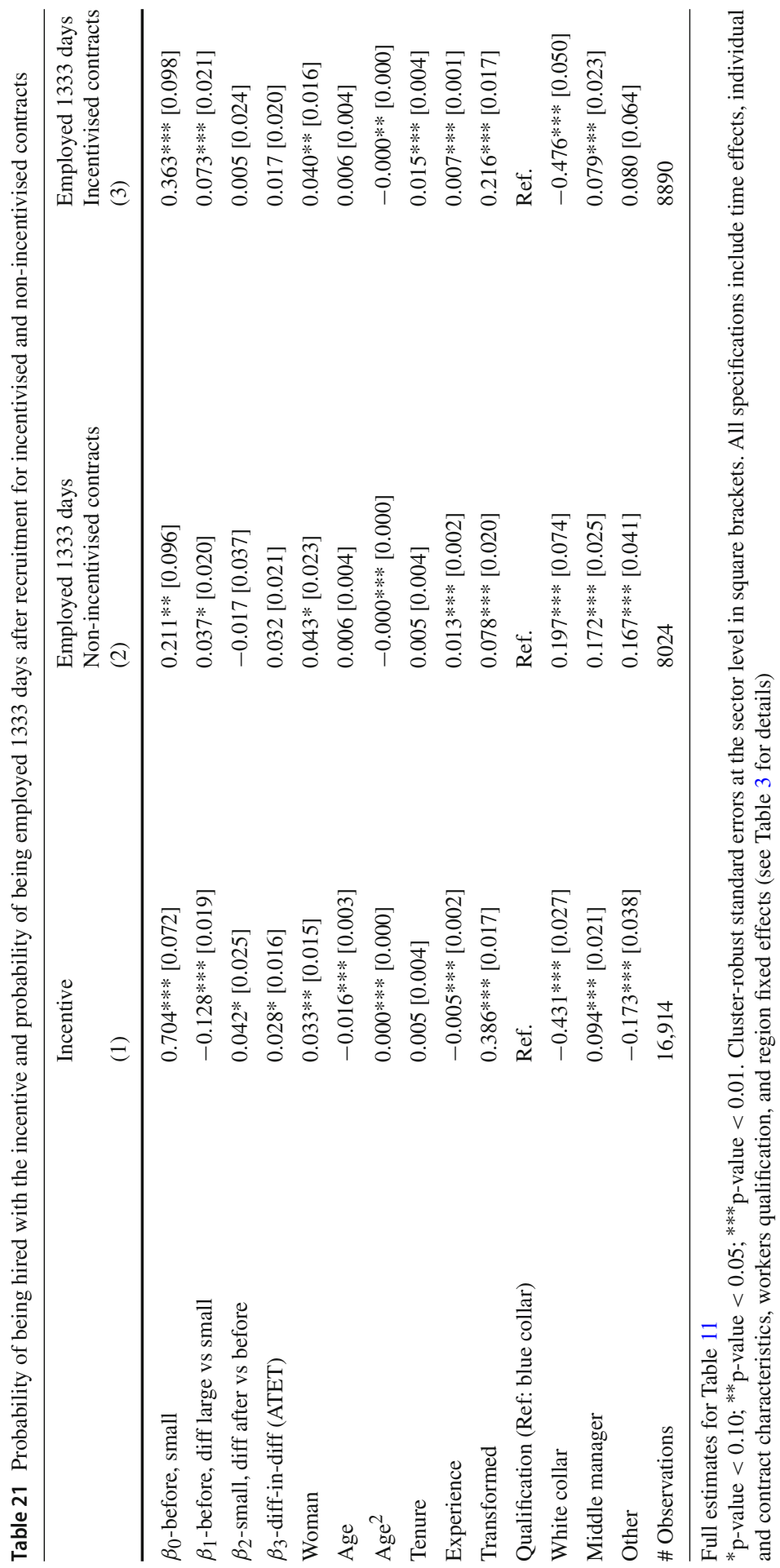




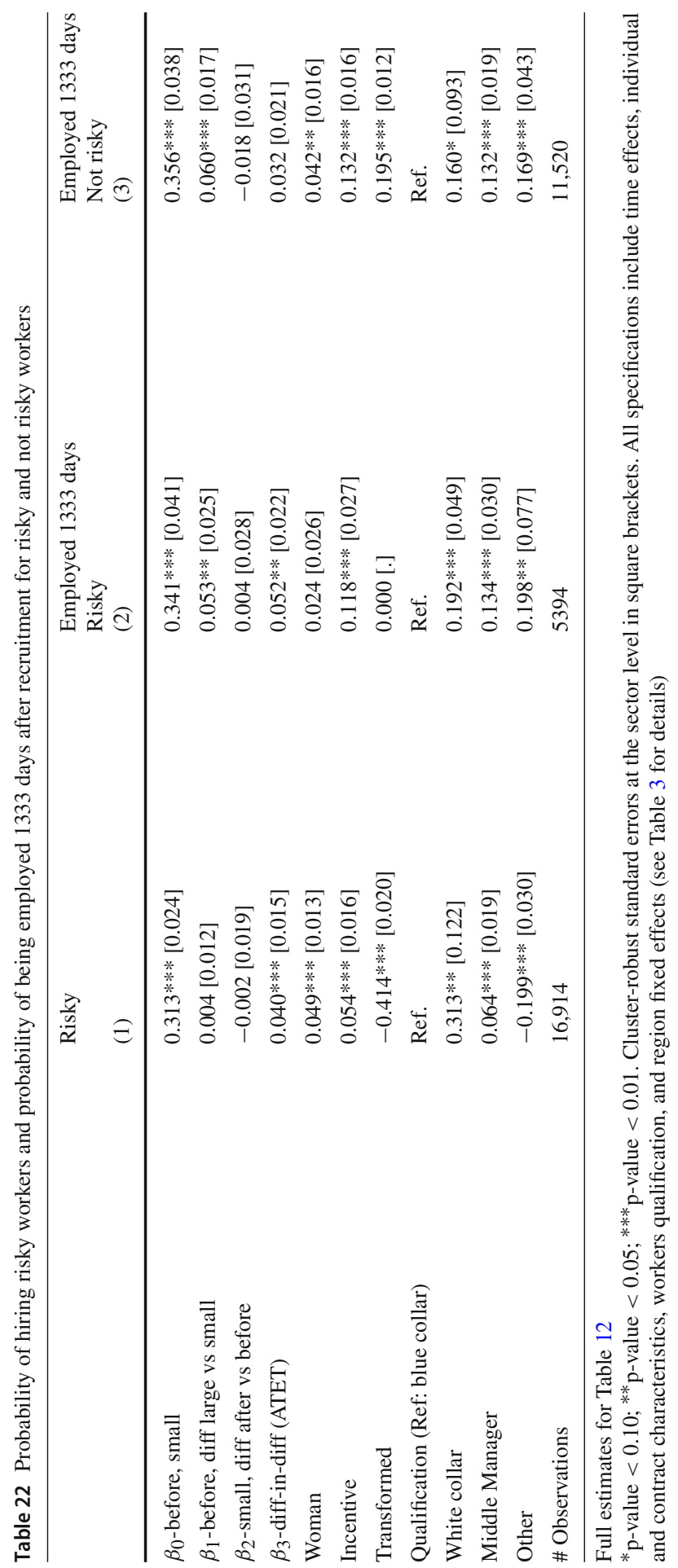




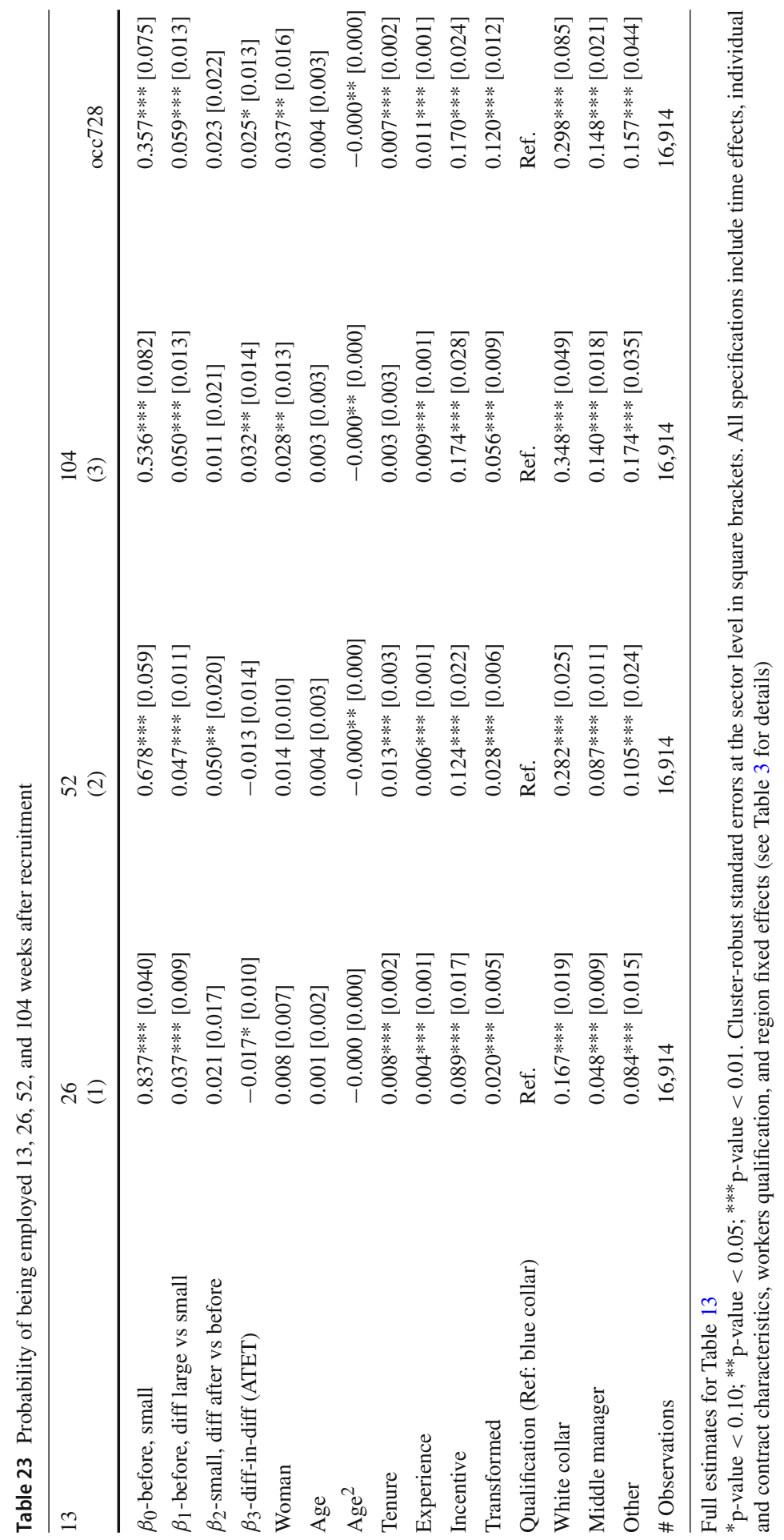




\section{References}

Ai C, Norton EC (2003) Interaction terms in logit and probit models. Econ Lett 80(1):123-129

Angrist JD, Pischke JS (2009) Mostly harmless econometrics. Princeton University Press, New York

Autor DH (2003) Outsourcing at will: the contribution of unjust dismissal doctrine to the growth of employment outsourcing. J Lab Econ 21(1):1-42

Autor DH, Kerr WR, Kugler AD (2007) Does employment protection reduce productivity? Evidence from US states. Econ J 117(521):189-217

Bentolila S, Bertola G (1990) Firing costs and labour demand: how bad is eurosclerosis? Rev Econ Stud 57(3):381-402

Boeri T, Garibaldi P (2019) A tale of comprehensive labor market reforms: evidence from the Italian jobs act. Lab Econ 1-16 (In press)

Boeri T, Jimeno JF (2005) The effects of employment protection: learning from variable enforcement. Eur Econ Rev 49(8):2057-2077

Cahuc P, Postel-Vinay F (2002) Temporary jobs, employment protection and labor market performance. Lab Econ 9(1):63-91

Cirillo V, Fana M, Guarascio D (2017) Labour market reforms in Italy: evaluating the effects of the jobs act. Econ Polit 34(2):211-232

Gambuzza M, Maschio S, Rasera M (2020) I contratti a tempo indeterminato tra incentivi e nuova regolazione: Persistenze e discontinuitÁ Technical Report I Tartufi n. 49, Veneto LAvoro

I contratti di lavoro dopo il Jobs Act (2016). Comitato Scientifico per il monitoraggio della riforma del mercato del lavoro. Technical Report QUADERNO DI MONITORAGGIO N.1/2016, Ministero del Lavoro e delle Politiche Sociali

Kugler A, Pica G (2008) Effects of employment protection on worker and job flows: evidence from the 1990 Italian reform. Lab Econ 15(1):78-95

Kugler AD, Saint-Paul G (2004) How do firing costs affect worker flows in a world with adverse selection? J Lab Econ 22(3):553-584

Lazear EP (1995) Hiring Risky Workers. NBER Working Papers 5334, National Bureau of Economic Research, Inc

Lechner M (2011) The estimation of causal effects by difference-in-difference methods. Found Trends Econ 4(3):165-224

Ljungqvist L (2002) How do lay-off costs affect employment? Econ J 112(482):829-853

Martins PS (2009) Dismissals for cause: the difference that just eight paragraphs can make. J Lab Econ 27(2):257-279

Moscarini G, Postel-Vinay F (2012) The contribution of large and small employers to job creation in times of high and low unemployment. Am Econ Rev 102(6):2509-39

OECD (2013) OECD indicators of employment protection. https://www.oecd.org/employment/emp/

Puhani PA (2012) The treatment effect, the cross difference, and the interaction term in nonlinear "differencein-differences" models. Econ Lett 115(1):85-87

Sestito P, Viviano E (2018) Firing costs and firm hiring: evidence from an Italian reform. Econ Policy 33(93):101-130

Wooldridge JM (2010) Econometric analysis of cross section and panel data. volume 1 of MIT Press Books. The MIT Press

Publisher's Note Springer Nature remains neutral with regard to jurisdictional claims in published maps and institutional affiliations. 